\title{
The effects of CO2-induced acidification on Tetraselmis biomass production, photophysiology and antioxidant activity: a comparison using batch and continuous culture
}

\author{
Coulombier Noémie ${ }^{1,}{ }^{*}$, Blanchier Paul ${ }^{2}$, Le Dean Loic ${ }^{2}$, Barthelemy Vanille ${ }^{2}$, Lebouvier Nicolas ${ }^{3}$, \\ Jauffrais Thierry ${ }^{2, *}$
}

${ }^{1}$ ADECAL Technopole, 1 bis rue Berthelot, 98846, Noumea, New Caledonia, French

2 Ifremer, IRD, Univ Nouvelle-Calédonie, Univ La Réunion, UMR 9220 ENTROPIE, BP 32078, 98800, Nouméa, New Caledonia, French

3 ISEA, EA7484, Université de la Nouvelle Calédonie, Campus de Nouville, 98851, Nouméa, New Caledonia, French

* Corresponding authors : Noémie Coulombier, email address : noemie.coulombier@adecal.nc ; Thierry Jauffrais, email address : thierry.jauffrais@ifremer.fr

\begin{abstract}
:
A Tetraselmis sp. was selected for its antioxidant activity owing to its high lipid peroxidation inhibition capacity. With the aim to monitor culture conditions to improve antioxidant activity, effects of $\mathrm{CO} 2$-induced acidification on Tetraselmis growth, elemental composition, photosynthetic parameters and antioxidant activity were determined. Two $\mathrm{pH}$ values were tested (6.5 and 8.5$)$ in batch and continuous cultures in photobioreactors. Acidification enhanced cell growth under both culture methods. However, the microalgae physiological state was healthier at $\mathrm{pH} 8.5$ than at $\mathrm{pH}$ 6.5. Indeed, photosynthetic parameters measured with pulse amplitude modulated (PAM) fluorometry showed a decrease in the photosystem II (PSII) efficiency at $\mathrm{pH} 6.5$ in batch culture. Yet, with the exception of the PSII recovering capacity, photosynthetic parameters were similar in continuous culture at both $\mathrm{pH}$. These results suggest that lowering $\mathrm{pH}$ through $\mathrm{CO} 2$-induced acidification may induce a lower conversion of light to chemical energy especially when coupled with $\mathrm{N}$-limitation and/or under un-balanced culture conditions. The highest antioxidant activity was measured in continuous culture at $\mathrm{pH} 6.5$ with an IC50 of $3.44 \pm 0.6 \mu \mathrm{g} \mathrm{mL-1}$, which is close to the IC50 of reference compounds (trolox and a-tocopherol). In addition, the principal component analysis revealed a strong link between the antioxidant activity and the culture method, the photophysiological state and the nitrogen cell quota and $\mathrm{C}: \mathrm{N}$ ratio of Tetraselmis sp.. These results highlight Tetraselmis sp. as a species of interest for natural antioxidant production and the potential of PAM fluorometry to monitor culture for production of biomass with a high antioxidant activity.
\end{abstract}




\section{Highlights}

- Tetraselmis has a higher antioxidant activity in balanced culture in acidic condition. $\mathrm{CO}_{2}$-acidification enhances Tetraselmis growth in batch and continuous culture. Culture mode and $\mathrm{CO}_{2}$-acidification have interactive effects on Tetraselmis physiology. $\mathrm{CO}_{2}$-acidification with $\mathrm{N}$-limitation induce a decrease of photosynthetic parameters. $\mathrm{CO}_{2}$-acidification and culture mode are effective tools to optimize antioxidant activity.

Keywords : phytoplankton, chlorophyll a fluorescence, non photochemical quenching, photosystem II efficiency, TBARS assay 
Abbreviations: Ek: Light saturation index; Fv/Fm: Maximum photosystem II efficiency; IC $_{50}$ :inhibition concentration 50; NPQ: non photochemical quenching; NPQ induc.: non photochemichal quenching induced by the rapid light curves; PBR: photobioreactor; PCA: principal component analysis; PSII: photosystem II; PUFA: poly unsaturated fatty acid; QC: cell carbon content; QN: cell nitrogen content; rETR: maximum relative electron transport rate; RLC: rapid light curve; ROS: reactive oxygen species; RQE: relative quantum efficiency; TBARS: thiobarbituric acid reactive substances

\section{Keywords}

phytoplankton; chlorophyll $a$ fluorescence; non photochemical quenching; photosystem II efficiency; TBARS assay

\section{Introduction}

Many natural products isolated from microalgae have attracted attention owing to their broad spectrum of biological activities with health promoting effects. Microalgae produce specific metabolites that can be used in cosmetics and pharmaceuticals; they have bioactive compounds with anti-UV, antibacterial, antifungal, anticancer, anti-inflammatory and/or antioxidant activities (Abad et al., 2008; Assunção et al., 2016; Safafar et al., 2015; Sathasivam and Ki, 2018; Talero et al., 2015; Yuan et al., 2011). In addition, PUFAs (e.g., the omega-3 or -6 fatty acids), pigments (e.g., carotenoids), vitamins, sterols and polysaccharides from microalgae origin are key molecules to develop dietary supplements in human nutrition and to improve animal feed (Aklakur, 2016; A. Catarina Guedes et al., 2011; Ana Catarina Guedes et al., 2011; Plaza et al., 2008).

Microalgae are currently studied as a potential source of natural antioxidant (Assunção et al., 2016; Goiris et al., 2012), as they could replace synthetic antioxidants in the food industry (Batista et al., 2019, 2017; Goiris et al., 2015a), and in the cosmetic, pharmaceutical and nutraceutical industries (A. Catarina Guedes et al., 2011; Sansone and Brunet, 2019). In addition, microalgae biodiversity, productivity and controlled culture conditions offer great potentials to produce a sustainable source of natural antioxidants (A. Catarina Guedes et al., 2011; Mimouni et al., 2012; Wijffels et al., 2010).

Recent screening showed that the antioxidant capacity of microalgae is species specific (Assunção et al., 2016; Coulombier et al., 2020; Custódio et al., 2012; Goiris et al., 2012). A Tetraselmis sp. isolated in New Caledonia was identified as a promising species for antioxidant production (Coulombier et al., 2020) owing to its high capacity to inhibit lipid peroxidation, growth rate, and ease of culture. In addition, Tetraselmis spp. were also identified for their antioxidant potentials in other screening (Assunção et al., 2016; Custódio et al., 2012; Goiris et al., 2012). This genus is cosmopolitan and can be found in different types of ecosystems, from oceanic to freshwater and hypersaline habitats (Fon-Sing and Borowitzka, 2016; Worden et al., 2004). Many Tetraselmis species have a high growth rate and dietary value of interest (e.g., polyunsaturated fatty acids, vitamins) for aquafeed formulation, fish, live feed, and shellfish nutrition (Cerezuela et al., 2012; Hemaiswarya et al., 2011; Ponis et al., 2003; Thinh et al., 1999), thus it is a genus exploited in aquaculture (e.g., T. chui, T. suecica). 
Concerning biotechnological applications, this genus is known to have a high content of bioactive compounds with antioxidant properties such as carotenoids (Ahmed et al., 2014), polyunsaturated fatty acids (Custódio et al., 2012), water soluble polysaccharides (Dogra et al., 2017), phenolic compounds (Farahin et al., 2016; Gam et al., 2020) and vitamins (Brown et al., 1999). Depending on abiotic stressors, microalgae can induce the production of antioxidant molecules to protect its organelles against ROS. This ability can then be used to enhance the production of specific metabolites of interest (Chen et al., 2017; Paliwal et al., 2017). Indeed, nutrient availability (Goiris et al., 2015b), light condition (Coulombier et al., 2020), pH and temperature (A.C. Guedes et al., 2011) are abiotic factors that influence the antioxidant activity and productivity of microalgae. However, few studies assessed the effect of $\mathrm{pH}$ or $\mathrm{CO}_{2}$-induced acidification on microalgae antioxidant activity (A.C. Guedes et al., 2011; Xia et al., 2018). Yet, $\mathrm{pH}$ and $\mathrm{CO}_{2}$-induced acidification affects dissolved inorganic carbon availability, intracellular acid base balance, structural rearrangement of pigment systems, and therefore, may influence growth, carbon assimilation, energy demand to maintain the membrane electrochemical potential and enzyme activity, and intracellular oxidative stress (Goss and Garab, 2001; Kramer et al., 2003; Milligan et al., 2009; Xia et al., 2018). Changes in carbon fixation will also modify the cellular concentration of ATP and NADPH, which in turn may modify photochemical processes and energy dissipation pathways (Takahashi and Murata, 2005). To monitor these photochemical processes (mainly PSII), PAM fluorometry is a commonly used technique based on chlorophyll fluorescence which offers the advantage to be non-invasive (Krause and Weis, 1991; Schreiber et al., 1995) and suitable in microalgal biotechnology to follow large scale culture fitness (Masojídek et al., 2010). This technique measure the light energy emitted from the light harvesting pigments associated with the process of photosynthesis. Briefly light energy absorbed by chlorophyll is either used by the photochemistry (photosynthesis), dissipated as heat (excess of energy) or re-emitted (fluorescence); consequently, by measuring the yield of fluorescence, information about the fitness of the PSII can be estimated (reviewed in Maxwell and Johnson 2000; Consalvey et al. 2005).

Culture conditions are modulating factors to which microalgae cell will respond by adjusting their physiology inducing modifications in growth, photosynthetic parameters, biomass composition and consequently antioxidant activity (Coulombier et al., 2020). In this study, we focus on the effects of $\mathrm{pH}$ using $\mathrm{CO}_{2}$-induced acidification on antioxidant activity and physiological responses of a tropical strain of Tetraselmis sp. produced in stirred closed photobioreactor operated in batch and in continuous culture. The overall objectives were to assess the effect of $\mathrm{pH}$ and culture mode on growth, photosynthetic parameters, and elemental composition to suggest marker processes of antioxidant activity of Tetraselmis sp. and to optimize production of biomass with high antioxidant activity.

\section{Materials and methods}

\subsection{Microalgae culture}

The microalgae Tetraselmis sp. was isolated from tropical coastal seawater (New Caledonia) (Coulombier et al., 2020). The inoculum was cultured in a $250 \mathrm{~mL}$ Erlenmeyer flask with filtered seawater (salinity $35 ; 0.2 \mu \mathrm{m}$ ) enriched in Conway medium (Walne, 1966). The cultures were exposed to a continuous light intensity of $190 \mu$ mol photons $\mathrm{m}^{-}$ ${ }^{2} \mathrm{~s}^{-1}$, aerated, and gently homogenized daily for 11 days.

\subsection{Experimental culture conditions}

Continuous and batch cultures were carried out in six $2.5 \mathrm{~L}$ stirred closed PBRs made of transparent polymethylmethacrylate (Jauffrais et al., 2013) and operated under the following conditions. The pH was regulated 
at 8.5 or 6.5 using automated $\mathrm{CO}_{2}$ addition and the temperature was kept constant at $25^{\circ} \mathrm{C}$. Temperature and $\mathrm{pH}$ conditions were set on an Arduino electronic card and followed with a Raspberry PI computer. The light was continuously provided on one side of the PBR using neon light tubes at $280 \mu \mathrm{mol}$ photons $\mathrm{m}^{-2} \mathrm{~s}^{-1}$. A Rushton turbine was used to homogenize the culture medium at $80 \mathrm{rpm} \mathrm{min}^{-1}$ and aeration was done by bubbling the culture with $0,2 \mu \mathrm{m}$ filtered air $\left(1 \mathrm{~L} \mathrm{~min}^{-1}\right)$ administered using stainless steel tube. Prior inoculation, photobioreactors were sterilized with peroxyacetic acid at $5 \mathrm{ppm}$ for $20 \mathrm{~min}$ and rinsed twice with filtered seawater $(0.2 \mu \mathrm{m})$. The photobioreactors were then inoculated with $125 \mathrm{~mL}$ of Tetraselmis sp. in filtered seawater enriched with $1 \mathrm{~mL} \mathrm{~L}^{-1}$ of Conway medium (Walne, 1966) to reach an initial concentration of $\sim 1.5 \times 10^{5}$ cell $\mathrm{mL}^{-1}$. The dilution rate of continuous cultures was fixed and maintained at 0.5 day $^{-1}$ after the fourth day of culture.

\subsection{Photosynthetic parameters}

Maximum PSII quantum efficiency (Fv/Fm), rapid light curves (RLC) and Non-Photochemical Quenching (NPQ) were measured daily to provide an overview of the physiological state of Tetraselmis sp..

Photosynthetic parameters were measured with a PAM fluorometer (AquaPen-C AP 110-C of Photon Systems Instruments, Czech Republic) with a blue light at $455 \mathrm{~nm}$. A dark adaptation of 1 hour was performed before all the measurements. Fv/Fm was measured with a saturating pulse $\left(3000 \mu \mathrm{mol}\right.$ photons $\left.\mathrm{m}^{-2} \mathrm{~s}^{-1}\right)$ and according to the equation 1 (Schreiber et al., 1995):

$$
\frac{\mathrm{Fv}}{\mathrm{Fm}}=\frac{\mathrm{Fm}-\mathrm{F} 0}{\mathrm{Fm}},
$$

where Fv is variable fluorescence, Fm is maximum fluorescence and F0 is the dark-adapted minimum fluorescence yield.

The rapid light curves were performed with seven incremental irradiances steps $(10 ; 20 ; 50 ; 100 ; 300 ; 500$ and $1000 \mu \mathrm{mol}$ photons $\mathrm{m}^{-2} \mathrm{~s}^{-1}$ ) of $60 \mathrm{~s}$. The phytoplankton physiological parameters were estimated by adjusting the model by Platt et al. (1981) to the experimental data:

$$
\operatorname{rETR}(\mathrm{I})=\operatorname{rETRmax} \times\left(1-\mathrm{e}^{\left(-\alpha \times \frac{\mathrm{I}}{\mathrm{rETRmax}}\right)}\right),
$$

where rETRmax (AU) is the maximum relative electron transport rate, alpha $(\alpha)$ the initial slope of the RLC at limiting irradiance and Ek the light saturation index $\left(\mu \mathrm{mol}\right.$ photons $\left.\mathrm{m}^{-2} \mathrm{~s}^{-1}, \mathrm{Ek}=\mathrm{rETRmax} / \alpha\right)$.

NPQ induced by the rapid light curve was calculated according to the Stern Volner NPQ (Williamson et al., 2018) and according to the following equation:

$$
\mathrm{NPQ} \text { induc }=\frac{\mathrm{Fm}-\mathrm{Fm}^{\prime}}{\mathrm{Fm}^{\prime}},
$$

where Fm is the maximum fluorescent yield and Fm' the maximum fluorescent yield in actinic light measured at the final RLC step.

NPQ was also measured to assess the recovery of Tetraselmis sp. reaction centers to 5 successive light pulses of $60 \mathrm{~s}$ with a saturating light of $3000 \mu \mathrm{mol}$ photons $\mathrm{m}^{-2} \mathrm{~s}^{-1}$ and 3 dark recovery phases of $88 \mathrm{~s}$.

Using the acquired data, the relative quantum efficiency (Williamson et al., 2018) was calculated to allow comparison and assess recovery dynamics between the two $\mathrm{pH}$ conditions:

$$
\mathrm{RQE}=\frac{\mathrm{Fq}^{\prime} \div \mathrm{Fm}^{\prime}}{\mathrm{Fv} \div \mathrm{Fm}} \times 100
$$

where $\mathrm{Fq}^{\prime}$ is the fluorescence quenched in actinic light $\left(\mathrm{Fq}^{\prime}=\mathrm{Fm}^{\prime} / \mathrm{F}^{\prime}\right), \mathrm{F}^{\prime}$ is the fluorescent yield in actinic light.

\subsection{Cell growth measurements}


Cell growth was followed daily by optical density at $680 \mathrm{~nm}$ to measure pigment absorption (chlorophyll $a$ ), at $800 \mathrm{~nm}$ for cell compounds absorption and by counting cells using Malassey hemocytometer under a Leica DM750 microscope (x20) (Leica Microsystems, Germany).

For the batch cultures, using the growth kinetics, a Gompertz model (Equation 5) was fitted to the data (Jauffrais et al., 2017) to assess the maximum growth rate ( $\mu$ max in day ${ }^{-1}$ ), the maximum cell concentration ( $\alpha$ expressed in $\ln (\mathrm{Ct} / \mathrm{C} 0)$ with $\mathrm{Ct}$ and $\mathrm{C} 0$ in cell $\left.\mathrm{mL}^{-1}\right)$ and the latency time ( $\lambda$ in day, if present) using MatLab software:

$$
F(t)=\alpha \times \exp (-\exp (\mu \max \times \exp (1) / \alpha \times(\lambda-t)+1)),
$$

\subsection{Sampling for elemental composition, nutrient and antioxidant analyses}

For the batch cultures, approximatively $500 \mathrm{~mL}$ of culture medium at the beginning of the stationary phase (day 6), and the 2 liters left in late stationary phase (day 18) were collected in each PBR for analyses.

For the continuous cultures, in each PBR and at steady states (i.e., less than $10 \%$ variation of cellular concentration and absorbance during at least three days) $1.25 \mathrm{~L}$ was collected daily and over three days for analyses at $\mathrm{pH} 8.5$ and 6.5 respectively.

\subsubsection{Elemental analysis}

All the equipment used for handling was placed in a furnace at $400{ }^{\circ} \mathrm{C}$ for 4 hours to avoid carbon or nitrogen contamination. Aliquots $(3,4$ or $5 \mathrm{~mL}$ ) of culture medium were filtered through pre-combusted glass fiber filters $(1.2 \mu \mathrm{m}$, Whatman $\mathrm{GF} / \mathrm{C})$, dried at $70{ }^{\circ} \mathrm{C}$ for $24 \mathrm{~h}$, placed in pre-combusted glass tubes and kept at $-20{ }^{\circ} \mathrm{C}$ until analysis. The samples were analyzed using an elemental analyzer (SERCON Integra 2, United Kingdom). C:N ratio was calculated by dividing cell carbon content (QC) by cell nitrogen content (QN), to assess nitrogen and carbon status of Tetraselmis.

\subsubsection{Residual $\mathrm{NOX}_{\mathrm{X}}$ and $\mathrm{PO}_{4}$ analysis}

Approximatively $10 \mathrm{~mL}$ of the culture medium were filtered through $0.22 \mu \mathrm{m}$ syringe filters in a $15 \mathrm{~mL}$ falcon tubes and kept at $-20{ }^{\circ} \mathrm{C}$ until $\mathrm{NOx}\left(\mathrm{NO}_{3}+\mathrm{NO}_{2}\right)$ and $\mathrm{PO}_{4}$ analysis. The nutrients were analyzed using a continuous-flow auto-analyzer (AA3 Seal Analytical, United Kingdom).

\subsubsection{Antioxidant analysis}

The leftover of culture was collected by centrifugation $\left(4500 \mathrm{rpm}, 5 \mathrm{~min}, 4^{\circ} \mathrm{C}\right)$, lyophilized and kept at $-80^{\circ} \mathrm{C}$ until extraction. Freeze dried biomass of each sample $(50 \mathrm{mg}$ ) was first grounded using a pestle and a mortar in the dark at room temperature and suspended in $5 \mathrm{~mL}$ of methanol/dichloromethane mixture $(50: 50 \mathrm{v} / \mathrm{v})$. Then, the extracts were submitted to ultrasound for 10 minutes in an ice bath, and were filtered. This process was repeated until the biomass became colorless, then the extracts were pooled, dried under a steam of nitrogen, and stored at $-80^{\circ} \mathrm{C}$ until antioxidant analysis using lipid peroxidation inhibition assay (TBARS assay). The method adapted from Ahmed et al. (2015) was applied on Tetraselmis sp. extracts (Coulombier et al., 2020). Briefly, Fe-ascorbate system was used for oxidation catalysis and linoleic acid as unsaturated fatty acid. Linoleic acid $(0.2 \mathrm{~mL})$ was emulsified with Tween $20(0.4 \mathrm{~mL})$ and phosphate buffer $(19.4 \mathrm{~mL}, 20 \mathrm{mM}, \mathrm{pH} 7.4)$. Microalgae dried extracts (1.25 to $\left.200 \mu \mathrm{g} \mathrm{mL}^{-1}\right)$ or standards ( 0.03 to $\left.5 \mu \mathrm{g} \mathrm{mL}^{-1}\right)$ were resuspended in $0.5 \mathrm{~mL}$ of ethanol. Then phosphate buffer $(0.6 \mathrm{~mL})$, ascorbic acid $(0.2 \mathrm{~mL}, 0.01 \%), \mathrm{FeSO}_{4}(0.2 \mathrm{~mL}, 0.01 \%)$, and linoleic emulsion $(0.5 \mathrm{~mL})$ were added successively and the mixture was incubated at $37^{\circ} \mathrm{C}$ for $24 \mathrm{~h}$. Subsequently, the oxidation was stopped by mixing $0.4 \mathrm{~mL}$ of the extract with 
butylated hydroxytoluene (BHT) $(0.04 \mathrm{~mL}, 0.4 \%)$ and then $0.44 \mathrm{~mL}$ of a solution of thiobarbituric acid (TBA, $0.8 \%)$ and trichloroacetic acid (TCA, $4 \%$ ) was added. The samples were then placed at $100^{\circ} \mathrm{C}$ for 30 minutes, cooled and centrifuged. The absorbance of the supernatant was then measured at $534 \mathrm{~nm}$. The percentage of inhibition of linoleic acid peroxidation and inhibition concentration $\left(\mathrm{IC}_{50}\right)$ values were finally calculated (Coulombier et al., 2020).

\subsection{Data analysis}

Data are expressed as mean \pm standard error (SE). After testing for homogeneity of variance and normality (test Kolmogorov-Smirnov), statistical analyses to assess differences among treatments consisted of a one-way or twoway analysis of variance (ANOVA) followed by a Fisher's LSD test, or of Kruskal-Wallis tests. A general linear model was also used to assess differences between treatments, sampling days, and time points generated by repeated NPQ measurement during the NPQ induction by actinic light and dark recovery period. Differences were considered significant at $\mathrm{p}<0.05$.

Additionally, to analyze the potential influence of experimental factors ( $\mathrm{pH}$, mode of culture), photophysiological state, nutrients and elemental quota on antioxidant activity $\left(\mathrm{IC}_{50}\right)$, a Principal Component Analysis (PCA) was performed. All statistical data analyses were carried out using Statgraphics Centurion XV.I (StatPoint Technologies, Inc., United States).

\section{Results}

\subsection{Growth performances}

Low pH had a significant influence on the growth ( $\mu$ max, table 1) of Tetraselmis sp. cultured in batch as $\mu$ max increased from $1.48 \pm 0.16$ day $^{-1}$ at $\mathrm{pH} 8.5$ to $2.45 \pm 0.18$ day $^{-1}$ at $\mathrm{pH} 6.5$, but the latency time (lambda) was slightly higher at low $\mathrm{pH}(0.44 \pm 0.04$ day $)$ than at $8.5(0.18 \pm 0.03$ day, Table 1$)$. However, the maximum concentration (Cmax) was similar between the two conditions, $7.10 \pm 0.02 \times 10^{6}$ cells $\mathrm{mL}^{-1}$ at $\mathrm{pH} 8.5$ and $7.52 \pm 0.02 \times 10^{6}$ cells $\mathrm{mL}^{-1}$ at $\mathrm{pH} 6.5$ (Table 1 and Fig. $1 \mathrm{~A}$ and $\mathrm{C}$ ). In continuous culture at pH 8.5 , the steady state was maintained from day 6 to 19 at a cell concentration around 2.3-2.8 $\times 10^{6}$ cells $\mathrm{mL}^{-1}$. The cell concentration quickly raised to $4.0-5.5$ cells $\mathrm{mL}^{-1}$ at $\mathrm{pH} 6.5$ but cell concentration and absorbance at steady state were less stable than at $\mathrm{pH} 8.5$ (Fig 1B and D).

\subsection{Elemental and residual nutrient analyses}

The cell carbon content (QC) was not significantly affected by $\mathrm{pH}\left(\mathrm{F}_{1,25}=2.16, \mathrm{P}=0.16\right)$; whereas, the mode of culture (batch vs continuous culture) had a significant effect on the carbon cell quota $\left(\mathrm{F}_{1,25}=6.97, \mathrm{P}=0.0 .15\right)$, with lower QC in continuous culture at steady state than in batch culture at stationary phase (Fig. 2A). The cell nitrogen content $(\mathrm{QN})$ was affected by both $\mathrm{pH}\left(\mathrm{F}_{1,25}=6.96, \mathrm{P}=0.015\right)$ and the mode of culture $\left(\mathrm{F}_{1,25}=86.91, \mathrm{P}<0.001\right)$, with higher QN in continuous culture and particularly at $\mathrm{pH} 8.5\left(0.37 \pm 0.6 \mathrm{fmol} \mathrm{cell}^{-1}, \mathrm{Fig}\right.$. $\left.2 \mathrm{~B}\right)$. The C:N ratio (Fig. 2C) was thus significantly lower in continuous culture compared to batch culture $\left(\mathrm{F}_{1,25}=670, \mathrm{P}<0.001\right)$, but significant differences between $\mathrm{pH}$ were only observed in continuous culture $\left(\mathrm{F}_{1,16}=7.26, \mathrm{P}=0.017\right)$. 
Dissolved NOx and phosphate persisted in the medium throughout all experiments, but NOx concentration was low $(0.60 \pm 0.07 \mu \mathrm{mol} \mathrm{L}-1)$ indicating N-limitation; whereas, phosphate was always higher than NOx indicating no P-limitation $\left(1.98 \pm 0.72 \mu \mathrm{mol} \mathrm{L}{ }^{-1}\right)$.

\subsection{Photosynthetic parameters calculated from rapid light curves (RLCs)}

The Maximum PSII quantum efficiency (Fv/Fm, Fig. 3A) in batch cultures started at $0.57 \pm 0.01$ and quickly reached its highest value after one day of culture at $\mathrm{pH} 6.5(0.63 \pm 0.02)$, and after three days of culture at $\mathrm{pH} 8.5$ $(0.72 \pm 0.00)$. Then Fv/Fm decreased regularly until the end of the experiment; however, a faster decrease was observed at $\mathrm{pH} 6.5(0.38 \pm 0.03$ at the end $)$ than at $\mathrm{pH} 8.5(0.57 \pm 0.02)$. In continuous culture, no differences were observed between the two conditions, once steady state was reached, Fv/Fm remained stable around 0.66 from day 5 to the end of the experiment (Fig. 3B).

Four other photosynthetic parameters were followed over time and calculated from the RLCs: rETRmax (relative maximum electron transport rate), Ek (light saturation coefficient in $\mu \mathrm{mol}$ photons $\mathrm{m}^{-2} \mathrm{~s}^{-1}$ ), Alpha (maximum light utilisation coefficient for photosystem II), and NPQ induc (Non-Photochemical Quenching induced during the RLC).

In batch culture, the highest rETRmax $(174.4 \pm 7.2 \mathrm{AU})$ was measured at $\mathrm{pH}$ 6.5, during the exponential growth phase (Fig. 4A). At pH 8.5 a lower rETRmax was found (163.8 $\pm 4.1 \mathrm{AU})$ but a similar trend was observed. In both conditions, rETRmax declined sharply during the linear growth phase and slightly at the stationary phase. Moreover, the decline was significantly steeper at low pH than at pH 8.5 (Fig. 4A and Table 2). In continuous culture, rETRmax was stable and comparable under both conditions and reached values that were similar to the highest one measured in batch culture, $181.9 \pm 6.2$ and 176.0 $\pm 12.8 \mathrm{AU}$ at pH 8.5 and 6.5, respectively (Fig. 4B). In batch culture, Ek increased quickly to reach a maximum during the exponential growth phase followed by biphasic decrease, a sharp one during the linear growth phase that slowly stabilized reaching the stationary phase (Fig. 4C). The highest value was reached at day 2 at $\mathrm{pH} 6.5\left(521.7 \pm 5.2 \mu \mathrm{mol}\right.$ photons $\left.\mathrm{m}^{-2} \mathrm{~s}^{-1}\right)$ and at day 3 at $\mathrm{pH}$

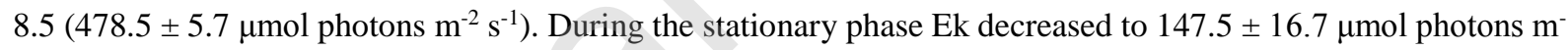
${ }^{2} \mathrm{~s}^{-1}$ and $134.5 \pm 11.2 \mu \mathrm{mol}$ photons $\mathrm{m}^{-2} \mathrm{~s}^{-1}$ at $\mathrm{pH} 6.5$ and 8.5, respectively. Contrary to the batch culture, in continuous culture, Ek stayed stable and similar over time and between conditions, at 570-578 $\mu$ mol photons $\mathrm{m}^{-}$ ${ }^{2} \mathrm{~s}^{-1}$ (Fig. 4D).

Concerning the maximum light utilization coefficient (alpha, Fig. 4E), it fluctuated between $0.31 \pm 0.01$ to $0.39 \pm 0.01$ at $\mathrm{pH} 8.5$, while it declined until $0.18 \pm 0.02$ from the end of exponential growth phase to the end of the experience at $\mathrm{pH}$ 6.5. Similar alpha (0.32-0.30) were calculated in continuous culture at pH 8.5 and 6.5 (Fig. $4 \mathrm{~F})$.

Non-Photochemical Quenching induced by the RLCs (NPQ induc, Fig. 4G) was variable during both growth phases but kept increasing at pH 6.5 from day 2 to the end of the experiment $(1.68 \pm 0.08$ on day 18), whereas at $\mathrm{pH} 8.5$, once the stationary phase was reached, the NPQ induc stabilized between $0.92 \pm 0.23-1.31 \pm 0.17$. Similarly, to the other calculated photophysiological parameters, no differences were found in continuous culture (0.38-0.31, Fig. 4H). 


\subsection{Photosynthetic parameters calculated from NPQ data}

In batch culture, five days were monitored (Fig. 5) to assess photosynthetic recovery over time. Relative Quantum Efficiency (RQE) was calculated from Non-Photochemical Quenching (NPQ) data measured during the exponential growth phase (day 2), the linear growth phase (day 4) and during early to late stationary phase (days $6,11,18$ ). The NPQ and RQE showed significant differences owing to $\mathrm{pH}$, sampling day and time (Fig. 5A, B, D and $\mathrm{E}$ and Table 3). However, the magnitude of NPQ induction and recovery was greater at $\mathrm{pH} 6.5$ during stationary phase (day 11 and 18). Furthermore, the RQE decrease was clearly enhanced over the induction period at pH 6.5 at day 11 and 18 (e.g., $60.9 \pm 2.8$ on day $18,86.5 \pm 3.0$ on day 6; Fig. 5E) with an incomplete recovery during the dark recovery period compared to the other condition and sampling days. Interestingly, in continuous culture, NPQ and RQE curves showed similar trends during the induction and dark recovery periods but significant differences were observed (Table 3). The NPQ and RQE had lower values at $\mathrm{pH} 6.5$ than at $\mathrm{pH} 8.5$ (Fig. 5C and F), and the magnitude of the RQE decrease during the induction period was higher and with a slower recovery at pH 6.5.

\subsection{Antioxidant activity and elemental and residual nutrient analyses}

TBARS assay measures the capacity of Tetraselmis sp. extracts to inhibit the chain reaction of lipid peroxidation initiated by the ferrous-ascorbate system. In batch culture, no differences were observed between both $\mathrm{pH}$ conditions, but a higher inhibition of lipid peroxidation was observed at low $\mathrm{pH}$ in continuous culture. In addition, differences were observed between batch and continuous culture. The best $\mathrm{IC}_{50}$ were obtained in continuous culture at $\mathrm{pH}$ 6.5, (3.44 $\pm 0.6 \mu \mathrm{g} \mathrm{mL} \mathrm{m}^{-1}$, Fig. 6 and Table 4).

\subsection{PCA}

Biotic and abiotic factors influencing antioxidant activity $\left(\mathrm{IC}_{50}\right)$ in all samples collected in batch and continuous culture at pH 6.5 and 8.5 were further analyzed through PCA (Fig. 7). The first and second components accounted for $78 \%$ (58\% and $20 \%$ respectively) of the variability amongst all samples.

The first component, with an Eigen value of 7,5, distinguished high and low $\mathrm{IC}_{50}$ values mainly based on the culture method (batch $v$ s continuous) and on the photophysiological state of the PSII (Fv/Fm, rETRmax, EK, NPQ induc) and elemental composition (QN and C:N ratio). The second component, with an Eigen value of 2.6, clearly distinguished $\mathrm{IC}_{50}$ values owing to the effect of $\mathrm{pH}$, nutrient availability and of the capacity of the PSII to cope with low light (Alpha).

\section{Discussion}

\subsection{Growth performances and fitness}

Responses of microalgae to $\mathrm{CO}_{2}$-induced acidification are likely to be species specific, with potential "winners" and "losers" (Hinga, 2002). Tetraselmis F. Stein (1878) is a cosmopolitan genus known to live in a wide variety 
of habitats (Fon-Sing and Borowitzka, 2016; Worden et al., 2004). The species studied in this paper came from a coastal and transitional environment and is thus naturally exposed to sudden changes in pH (Wu et al., 2015). In culture, the effect of $\mathrm{pH}$ on a Tetraselmis sp. growth was studied in batch culture between $\mathrm{pH} 5.5$ and 9.5 by Khatoon et al. (Khatoon et al., 2014). This strain was found to grow in this large range of pH and was thus considered resistant to acidification of its culture medium. However, its optimum for growth, protein, lipid and carbohydrate content was situated between pH 7.5 and 8.5 in batch culture (Khatoon et al., 2014).

In the present study, we studied a Tetraselmis sp. cultured under two $\mathrm{pH}$ conditions, 6.5 and 8.5, and using two different modes of culture (batch and continuous) to assess the effect of $\mathrm{CO}_{2}$ acidification on biomass production and fitness, in addition to antioxidant activity. Low $\mathrm{pH}$ had a significant influence on growth in batch culture as the acidification of the culture medium enhanced Tetraselmis sp. specific growth rate ( $\mu$ max) by a factor of 1.65 . However, the difference of $\mathrm{pH}$ only had a negligible effect on the latency time (lambda) and maximum concentration (Cmax), as small or no differences were observed for these parameters. Similarly, in continuous culture the switch from $\mathrm{pH} 8.5$ to 6.5 significantly increased cell concentration by a factor of 1.6 ; however, looking at the data, the stability (cell concentration, DO) of the culture at steady state showed more variation at $\mathrm{pH} 6.5$ than at $\mathrm{pH}$ 8.5. In the present study, the acidification was $\mathrm{CO}_{2}$-induced. Even though $\mathrm{pCO}_{2}$ and dissolved inorganic carbon (DIC) were not monitored, chemical changes in seawater carbonate systems are known to occur through $\mathrm{CO}_{2}$ acidification including higher $\mathrm{CO}_{2}: \mathrm{HCO}_{3}{ }^{-}$ratio and increase of DIC (Hinga, 2002); the stimulated growth at pH 6.5 could be explained in two ways : (i) the increase in DIC provided more carbon for Tetraselmis for photosynthesis (Mackey et al., 2015; Wu et al., 2010) (ii) the downregulation of energetic cost $\mathrm{CO}_{2}$ concentrating mechanisms (CCMs) saved energy that may be allocated to support growth (Hu et al., 2017; Xiang et al., 2001). Indeed, marine microalgae assimilate inorganic carbon through the carboxylating enzyme Rubisco, which can only use $\mathrm{CO}_{2}$ as substrate. However, Rubisco have low affinity to $\mathrm{CO}_{2}$, and growth can be limited at high pH where dissolved inorganic carbon is mostly find as $\mathrm{HCO}_{3}{ }^{-}$and $\mathrm{CO}_{3}{ }^{2-}$. Therefore, microalgae have developed CCMs to increase $\mathrm{CO}_{2}$ concentration in the proximity of Rubisco that require energetic investment (Giordano et al., 2005). Microalgae biochemical composition is influenced by these physico-chemical variations of their culture medium, which is then reflected by their physiological state (Brown et al., 1997). This study clearly established that QC of Tetraselmis sp. was mainly affected by the mode of culture (batch vs continuous). Even if QC was always higher at $\mathrm{pH} 8.5$ than at $\mathrm{pH}$ 6.5, this difference was not significant, whereas QN was affected by both $\mathrm{pH}$ decrease by $\mathrm{CO}_{2}$ acidification and mode of culture, as it was 3-times fold higher in continuous culture than in batch culture, and 1.3-times fold higher in culture at $\mathrm{pH} 8.5$ than at $\mathrm{pH}$ 6.5. The $\mathrm{C}: \mathrm{N}$ ratio was therefore 3.1-times lower in continuous culture compared to batch culture, and a significant difference between $\mathrm{pH}$ was only observed in continuous culture. The standard elemental stoichiometry is generally assumed to be $106 \mathrm{C}: 16 \mathrm{~N}: 1 \mathrm{P}$ (Redfield, 1958); however, microalgae in culture have a wide flexibility in their C:N:P ratios depending on which nutrient was limited (Geider and La Roche, 2002). In our study, this ratio was mainly affected by the mode of culture (batch vs continuous), as a higher carbon and a lower nitrogen quotas were observed in batch culture compared to continuous culture. Although nitrate concentration in the culture medium was comparable between stationary phase of the batch culture and steady state of the continuous culture, the continuous supply in nitrate (and other nutrients) in continuous culture induced a higher QN and consequently a lower C:N. It results in typical C:N ratios of N-limited microalgae $(>15)$ in batch culture and N-non limited microalgae $(<10)$ in continuous culture (Rios et al., 1998). This effect on $\mathrm{C}: \mathrm{N}$ ratio is a common observation owing to nitrate deficiency: a decrease in $\mathrm{N}$ products, 
such as chlorophyll and proteins (up to 25\%), and an increase of carbon storage products, such as carbohydrates and eventually lipids (up to 50-60\% AFDW for both) (Jiang et al., 2012; Li et al., 2011).

The responses to $\mathrm{CO}_{2}$-induced acidification also lead to different photophysiological fitness. The observations can be modulated depending on the mode of culture used to produce Tetraselmis sp.. Indeed, differences due to $\mathrm{CO}_{2}$ acidification were enhanced in batch culture compared to continuous culture. Under both $\mathrm{pH}$ conditions in the batch culture, Fv/Fm increased during the exponential growth phase to stabilize and decrease once the stationary phase was reached. The Fv/Fm values are similar to those previously measured for eukaryotic microalgae cultivated in similar culture conditions (Barnett et al., 2015; Goiris et al., 2015b; Jauffrais et al., 2016; Menguy et al., 2020). Yet, Fv/Fm reached a lower maximum value and decreased faster at $\mathrm{pH} 6.5$ compared to $\mathrm{pH} 8.5$. However, this difference between quantum yields was not observed in continuous culture, where Fv/Fm remained stable over time independently of $\mathrm{pH}$. The maximum quantum efficiency of the PSII reflects photochemical processes that depend upon chloroplast reactions that use ATP and reductants provided by photosynthesis. It may therefore be sensitive to cell energy metabolism and interactions between carbon and nitrogen assimilation. However, the use of Fv/Fm to monitor a photophysiological stress may be controversial, e.g., to monitor nutrient stress in balanced systems (Napoleon et al., 2013). Nevertheless, Fv/Fm is still a useful indicator of environmental or nutritional stress of microalgae grown in batch cultures (Beardall et al., 2001; Gordillo et al., 2001; Jauffrais et al., 2016) and is commonly used as an indicator to asses $\mathrm{pH}$ and/or $\mathrm{CO}_{2}$ effect on photochemical processes of phytoplankton (Touloupakis et al., 2016; Wu et al., 2015). Our study seems to confirm these differences between balanced and unbalanced modes of culture. However, it also highlights that over time and under stable and balanced conditions (e.g., nutrients), Tetraselmis sp. is able to adapt and maintain its maximum quantum yield under $\mathrm{CO}_{2}$-acidified culture medium.

Similarly to Fv/Fm, the photosynthetic parameters calculated from the RLCs (rETRmax, Ek, Alpha and NPQ induc) highlight differences between the two-pH conditions only in batch culture whereas no difference was observed in continuous culture. At pH 6.5 in batch culture, the lower Fv/Fm, rETRmax and alpha, and the higher NPQ induc reflect an increased photo-stress and corresponding suppression of photochemistry. This photo-stress might be related, in batch culture, to low $\mathrm{pH}$ stress coupled with $\mathrm{N}$-limitation. Indeed, it is known that $\mathrm{N}$-limitation gradually causes a decrease in photosynthetic pigments (Geider et al., 1993) the decline of PSII maximum quantum yield (Fv/Fm) (Berges et al., 1996; Cleveland and Perry, 1987; Jauffrais et al., 2016) and the gradual inactivation of the protein D1 in PSII reaction centers owing to the reduced amount of N compounds to synthesize it. Protein D1 is an essential component in the electron transport chain and its turnover rate is frequently the limiting factor in PSII repair rates (reviewed in Campbell and Tyystjarvi(Campbell and Tyystjarvi, 2012). In addition, Nlimitation may reduce internal $\mathrm{pH}$ regulation mechanisms, to balance the external $\mathrm{pH}$ decrease, inducing acidification of intracellular compartments such as cytoplasm and chloroplast's stroma that could exerts numerous effects, in particular Rubisco inhibition (Miyachi et al., 2003; Solovchenko and Khozin-Goldberg, 2013). It could explain the greater Fv/Fm, rETRmax and alpha decrease and the NPQ induc increase at pH 6.5 compared to $\mathrm{pH}$ 8.5. (Ptushenko and Solovchenko, 2016).

Microalgae modulate their NPQ to tolerate and prevent long-lasting damage to photosynthetic components, owing to high or fluctuating levels of light, by dissipating the excess absorbed energy as heat (Lavaud et al., 2007; Lavaud and Kroth, 2006; Wu et al., 2012). However, excessive irradiance, either long or sudden, can reduce NPQ efficiency, leading to damage of the protein D1, decline in photosynthetic efficiency, chronic photoinhibition and 
production of ROS (Franklin and Forster, 1997). The studied species was isolated in a costal and tropical area (New Caledonia) where photosynthetic active radiations are often above $2000 \mu$ mol photons m-2 s-1. In addition, this strain is not known to be highly sensitive to high light intensity (Coulombier et al., 2020). However, $\mathrm{CO}_{2}$ induced acidification is known to influence NPQ and particularly to increase NPQ at high light level (Gao et al., 2012). NPQ and the relative quantum efficiency (RQE, e.i. the quantum efficiency as a proportion of Fv/Fm) were thus monitored under actinic light induction and dark recovery phases to allow comparison of induction and recovery dynamics between the two $\mathrm{pH}$ conditions and culture modes (Williamson et al., 2018).

In batch culture, both NPQ and RQE showed significant differences owing to $\mathrm{pH}$, sampling day and time. However, the magnitude of NPQ induction and recovery was greater at $\mathrm{pH} 6.5$ during stationary phase and the RQE decrease was clearly enhanced over the induction period with an incomplete recovery during the dark recovery period. These results in batch confirm the photo-stress triggered by both low $\mathrm{pH}$ and N-limitation.

In continuous culture, NPQ and RQE curves showed similar trends during the induction and dark recovery periods but significant differences were observed. The magnitude of the RQE decrease during the induction period was higher and with a slower recovery at $\mathrm{pH}$ 6.5. It highlights that independently of N-limitation and culture mode, the $\mathrm{CO}_{2}$-induced acidification to $\mathrm{pH} 6.5$ induced a higher sensitivity to photo-stress in Tetraselmis sp.. At $\mathrm{pH} 6.5$, there is more dissolve $\mathrm{CO}_{2}$ in the medium which may induce an intracellular acidification due to entry of $\mathrm{CO}_{2}$ into the cell. Low internal $\mathrm{pH}$ is known to provoke inhibition of Rubisco which reduces consumption of NADPH and ATP and decrease electron sink from the photosynthetic electron transport chain (Miyachi et al., 2003; Ptushenko and Solovchenko, 2016). In addition, NPQ (xanthophyll cycle and protonation of PsbS protein) is known to be triggered by acidification of the thylakoid lumen when chloroplasts are illuminated (Goss and Garab, 2001; Kramer et al., 2003). It could explain the negative impact of $\mathrm{CO}_{2}$ acidification on photophysiological parameters.

\subsection{Antioxidant activity}

All aerobic organisms have to deal with ROS. Furthermore, microalgae possess chloroplasts where ROS are formed via energy transfer from chlorophyll or via electron transfer. Indeed, ROS concentration controls the PSII activity and therefore photosynthesis and photoprotective responses (Foyer and Shigeoka, 2011; Smerilli et al., 2019, 2016). Environmental stress, such as $\mathrm{CO}_{2}$-induced acidification (Bautista-Chamizo et al., 2018) or Nstarvation (Çakmak et al., 2015; Chokshi et al., 2017; Zhang et al., 2013) are known to induce additional ROS production An efficient intracellular network composed of enzymes and antioxidant molecules is thus required to balance and adjust intracellular ROS concentration (Foyer and Noctor, 2005; Mittler, 2002). In addition, recent works on microalgae showed that a strong link exists between antioxidant molecules and photo-protective mechanisms (xanthophyll cycle and NPQ) in response to light (Cartaxana et al., 2013; Smerilli et al., 2019, 2016). In light of this data, we analyzed the effects of $\mathrm{CO}_{2}$-induced acidification and mode of culture on antioxidant activity of Tetraselmis.

The bio-complexity of antioxidant molecules in microalgae requires the use of specific antioxidant assays with different mechanisms of action to evaluate their right antioxidant potential (Carocho and Ferreira, 2013; Coulombier et al., 2020; Prior et al., 2005; Rodriguez-Amaya, 2010). Different tests (e.g., TBARS, ORAC, DPPH and ABTS) were used in our previous study (Coulombier et al., 2020), with variable sensitiveness to different antioxidant compounds (e.g., PUFAs, carotenoids, phenolic compounds). We found that the TBARS assay, which measures the capacity of an antioxidant to inhibit the chain reaction of lipid peroxidation, was the best assay to assess the antioxidant activity of Tetraselmis sp. extracts (Coulombier et al., 2020). In this study, the best IC $_{50}$ 
were obtained with reference compounds trolox $(0.24 \mu \mathrm{g} \mathrm{mL}-1)$ and $\alpha$-tocopherol $(1.30 \mu \mathrm{g} \mathrm{mL}-1)$; however, the $\mathrm{IC}_{50}$ found in continuous culture at low $\mathrm{pH}(3.44 \pm 0.6 \mu \mathrm{g} \mathrm{mL}-1)$ was close to the $\mathrm{IC}_{50}$ of these reference compounds. In addition, antioxidant activity was improved by a factor of 4.5 compared to our previous results where $\mathrm{IC}_{50}$ of Tetraselmis sp. extracts were equal to 15.43 and $22.77 \mu \mathrm{g} \mathrm{mL}-1$ under low and high light respectively. Furthermore, the capacity of Tetraselmis sp. extracts to inhibit lipid peroxidation was more than seven time higher than other microalgal extracts, e.g., Nitzschia sp. (24.63 $\mu \mathrm{g} \mathrm{mL}-1)$, and Nephroselmis sp. (31.40 $\mu \mathrm{g} \mathrm{mL-1)} \mathrm{(Coulombier} \mathrm{et} \mathrm{al.,} \mathrm{2020).}$

Considering TBARS assay, our previous results showed that carotenoids did not contribute to the antioxidant activity measured (Coulombier et al., 2020). Lipid peroxidation is known to be inhibited by phenolic compounds (Cho et al., 2003; Niki et al., 2005; Salah et al., 1995), $\alpha$-tocopherol, fatty acid compounds (Henry et al., 2002; Richard et al., 2008) and sterols (Gordon and Magos, 1983; Yoshida and Niki, 2003). However, phenolic compounds and $\alpha$-tocopherol are probably not the molecules involved in Tetraselmis sp. extract as no activities were found using DPPH and ABTS assays (Coulombier et al., 2020). Since Tetraselmis is a genus known for its high content in PUFAs (Brown et al., 1997) and sterols (Patterson et al., 1993) and as we used a mixture of $\mathrm{MeOH} / \mathrm{DCM}$ similar to the one used for lipid extraction (Cequier-Sánchez et al., 2008), a high concentration of sterols or PUFAs in the extracts could explain our results on antioxidant activities (Coulombier et al., 2020; Custódio et al., 2012; Lv et al., 2015). However, it needs to be confirmed by a bio-guided fractionation of the extracts to identify antioxidant compound(s). Nevertheless, microalgae whole biomass or crude extract are often use for nutraceuticals or aquaculture preparations, thus it is necessary to optimize global antioxidant activity of the biomass instead of a specific antioxidant molecule.

We analyzed the potential influence of experimental factors ( $\mathrm{pH}$, mode of culture), photophysiological state, nutrients and elemental quota on antioxidant activity $\left(\mathrm{IC}_{50}\right)$ with a PCA, the objective being to improve and monitor culture conditions for producing biomass with high antioxidant activity. The first component distinguished high and low $\mathrm{IC}_{50}$ values mainly based on the culture method (batch $v s$ continuous) and on the photophysiological state of the PSII (Fv/Fm, rETRmax, EK, and NPQ) and elemental composition (high QN and low C:N ratio); whereas, the second component clearly distinguished $\mathrm{IC}_{50}$ values owing to the effect of $\mathrm{pH}$, of nutrient availability and of the capacity of the PSII to cope with low light (Alpha).

In addition to $\mathrm{pH}$ and culture mode, results revealed a strong link between the state of the PSII and the antioxidant activity of Tetraselmis sp.. The availability in dissolved $\mathrm{N}$ and $\mathrm{P}$ is also a key factor to improve antioxidant activity of Tetraselmis sp..

To sum up, a higher antioxidant activity (low $\mathrm{IC}_{50}$ ) is observed in continuous culture where nutrients availability is balanced and where the microalgae are in great photophysiological state. However, these conclusions need to be taken with some care and further studies are necessary to clearly link PSII state with antioxidant molecules and activities to improve the use of PAM fluorometry to monitor microalgae for producing biomass with high antioxidant activity.

\section{Conclusions}

This study provides evidence of the interactive effects of $\mathrm{CO}_{2}$-induce acidification and nutrient availability on growth, photophysiological state of the PSII and antioxidant activity of Tetraselmis sp.. It also highlights the great potential of Tetraselmis sp. as an alternative source of natural antioxidant, as well as on the role of $\mathrm{pH}$ and nutrients 
as effective tools to enhance the production of biomass with high antioxidant activity. In addition, it suggests that PAM fluorometry might be used to monitor microalgae culture for antioxidant-rich biomass production.

Authors' contributions: Conceptualization and methodology: Noémie Coulombier, Paul Blanchier, Loïc Le Déan and Thierry Jauffrais.; Validation: Noémie Coulombier, Thierry Jauffrais, Nicolas Lebouvier; Formal analysis: Paul Blanchier, Thierry Jauffrais, Noémie Coulombier, Nicolas Lebouvier; Investigation: Paul Blanchier, Vanille Barthelemy, Noémie Coulombier, Thierry Jauffrais; Resources: Loïc Le Déan, Thierry Jauffrais; Data curation: Thierry Jauffrais; Writing — original draft preparation: Thierry Jauffrais, Noémie Coulombier; Writing—review and editing: Thierry Jauffrais, Noémie Coulombier, Nicolas Lebouvier, Loïc Le Déan, Paul Blanchier; Supervision: Thierry Jauffrais, Nicolas Lebouvier; Project administration: Loïc Le Déan; Funding acquisition: Loïc Le Déan, Thierry Jauffrais

Funding: The authors acknowledge the Province Nord, the Province Sud, the Government of New Caledonia and the Comité Interministériel de l'Outre-Mer (CIOM) for financial support through the AMICAL (Aquaculture of Microalgae in New CALedonie) 1 and 2 research programs, and The South Province of New Caledonia ( ${ }^{\circ} 26960$, $n^{\circ} 1546$ and $\left.n^{\circ} 9705\right)$ and the North Province of New Caledonia ( ${ }^{\circ} 609011-55$ and $\left.n^{\circ} 609011-54\right)$ delivered the sampling authorizations. We would like also to acknowledge Ifremer for financing the Master 2 thesis of Paul Blanchier.

Conflicts of interest: The authors declare no conflict of interest.

\section{Declaration of interests}

The authors declare that they have no known competing financial interests or personal relationships that could have appeared to influence the work reported in this paper.

Acknowledgments: We would like to thanks Anne Desnues and Philippe Gérard from the LAMA (LAboratoire des Moyens Analytiques) (IRD, Nouméa) for the elemental and nutrient analyses.

\section{References}

Abad, M.J., Bedoya, L.M., Bermejo, P., 2008. Natural marine anti-inflammatory products. Mini-Reviews in Medicinal Chemistry 8, 740-754. https://doi.org/10.2174/138955708784912148

Ahmed, F., Fanning, K., Netzel, M., Turner, W., Li, Y., Schenk, P.M., 2014. Profiling of carotenoids and antioxidant capacity of microalgae from subtropical coastal and brackish waters. Food Chemistry 165, 300-306. https://doi.org/10.1016/j.foodchem.2014.05.107

Ahmed, I.A., Mikail, M.A., bin Ibrahim, M., bin Hazali, N., Rasad, M.S.B.A., Ghani, R.A., Wahab, R.A., Arief, S.J., Yahya, M.N.A., 2015. Antioxidant activity and phenolic profile of various morphological parts of underutilised Baccaurea angulata fruit. Food Chemistry 172, 778-787. https://doi.org/10.1016/j.foodchem.2014.09.122

Aklakur, M., 2016. Natural antioxidants from sea: a potential industrial perspective in aquafeed formulation. Rev Aquacult 10, 385-399. https://doi.org/10.1111/raq.12167 
Assunção, M.F.G., Amaral, R., Martins, C.B., Ferreira, J.D., Ressurreição, S., Santos, S.D., Varejão, J.M.T.B., Santos, L.M.A., 2016. Screening microalgae as potential sources of antioxidants. Journal of Applied Phycology 1-13. https://doi.org/10.1007/s10811-016-0980-7

Barnett, A., Méléder, V., Blommaert, L., Lepetit, B., Gaudin, P., Vyverman, W., Sabbe, K., Dupuy, C., Lavaud, J., 2015. Growth form defines physiological photoprotective capacity in intertidal benthic diatoms. ISME J 9, 32-45. https://doi.org/10.1038/ismej.2014.105

Batista, A.P., Niccolai, A., Bursic, I., Sousa, I., Raymundo, A., Rodolfi, L., Biondi, N., Tredici, M.R., 2019. Microalgae as functional ingredients in savory food products: Application to wheat crackers. Foods 8, 611. https://doi.org/10.3390/foods8120611

Batista, A.P., Niccolai, A., Fradinho, P., Fragoso, S., Bursic, I., Rodolfi, L., Biondi, N., Tredici, M.R., Sousa, I., Raymundo, A., 2017. Microalgae biomass as an alternative ingredient in cookies: Sensory, physical and chemical properties, antioxidant activity and in vitro digestibility. Algal Research 26, 161-171. https://doi.org/10.1016/j.algal.2017.07.017

Bautista-Chamizo, E., Borrero-Santiago, A.R., De Orte, M.R., DelValls, Á., Riba, I., 2018. Effects of CO2 enrichment on two microalgae species: A toxicity approach using consecutive generations. Chemosphere 213, 84-91. https://doi.org/10.1016/j.chemosphere.2018.09.001

Beardall, J., Young, E., Roberts, S., 2001. Approaches for determining phytoplankton nutrient limitation: Aquatic Sciences 63, 44-69. https://doi.org/10.1007/PL00001344

Berges, J.A., Charlebois, D.O., Mauzerall, D.C., Falkowski, P.G., 1996. Differential Effects of Nitrogen Limitation on Photosynthetic Efficiency of Photosystems I and II in Microalgae. Plant Physiology 110, 689-696. https://doi.org/10.1104/pp.110.2.689

Brown, M.R., Jeffrey, S.W., Volkman, J.K., Dunstan, G.A., 1997. Nutritional properties of microalgae for mariculture. Aquaculture 151, 315-331. https://doi.org/10.1016/S0044-8486(96)01501-3

Brown, M.R., Mular, M., Miller, I., Farmer, C., Trenerry, C., 1999. The vitamin content of microalgae used in aquaculture. Journal of Applied Phycology 3, 247-255. https://doi.org/10.1023/A:1008075903578

Çakmak, Z.E., Ölmez, T.T., Çakmak, T., Menemen, Y., Tekinay, T., 2015. Antioxidant response of Chlamydomonas reinhardtii grown under different element regimes. Phycological Research 63, 202-211. https://doi.org/10.1111/pre.12096

Campbell, D.A., Tyystjarvi, E., 2012. Parameterization of photosystem II photoinactivation and repair. Biochimica et Biophysica Acta (BBA) - Bioenergetics 1817, 258-265. https://doi.org/10.1016/j.bbabio.2011.04.010

Carocho, M., Ferreira, I.C.F.R., 2013. A review on antioxidants, prooxidants and related controversy: Natural and synthetic compounds, screening and analysis methodologies and future perspectives. Food and Chemical Toxicology 51, 15-25. https://doi.org/10.1016/j.fct.2012.09.021

Cartaxana, P., Domingues, N., Cruz, S., Jesus, B., Laviale, M., Serôdio, J., Da Silva, J.M., 2013. Photoinhibition in benthic diatom assemblages under light stress. Aquatic Microbial Ecology 70, 87-92. https://doi.org/10.3354/ame01648

Cequier-Sánchez, E., Rodríguez, C., Ravelo, A.G., Zárate, R., 2008. Dichloromethane as a solvent for lipid extraction and assessment of lipid classes and fatty acids from samples of different natures. J. Agric. Food Chem. 56, 4297-4303. https://doi.org/10.1021/jf073471e

Cerezuela, R., Guardiola, F.A., Meseguer, J., Esteban, M.A., 2012. Enrichment of gilthead seabream (Sparus aurata L.) diet with microalgae: effects on the immune system. Fish Physiology and Biochemistry 38, 1729-1739. https://doi.org/10.1007/s10695-012-9670-9

Chen, B., Wan, C., Mehmood, M.A., Chang, J.-S., Bai, F., Zhao, X., 2017. Manipulating environmental stresses and stress tolerance of microalgae for enhanced production of lipids and value-added products-A review. Bioresource Technology 244, 1198-1206. https://doi.org/10.1016/j.biortech.2017.05.170

Cho, E.J., Yokozawa, T., Rhyu, D.Y., Kim, H.Y., Shibahara, N., Park, J.C., 2003. The Inhibitory Effects of 12 Medicinal Plants and Their Component Compounds on Lipid Peroxidation. Am. J. Chin. Med. 31, 907917. https://doi.org/10.1142/S0192415X03001648

Chokshi, K., Pancha, I., Ghosh, A., Mishra, S., 2017. Nitrogen starvation-induced cellular crosstalk of ROSscavenging antioxidants and phytohormone enhanced the biofuel potential of green microalga Acutodesmus dimorphus. Biotechnology for Biofuels 10, 60. https://doi.org/10.1186/s13068-017-0747-7

Cleveland, J.S., Perry, M.J., 1987. Quantum yield, relative specific absorption and fluorescence in nitrogen limited Chaetoceros gracilis. Marine Biology 94, 489-497. https://doi.org/10.1007/BF00431395

Consalvey, M., Perkins, R.G., Paterson, D.M., Underwood, G.J.C., 2005. Pam Fluorescence: A Beginners Guide for Benthic Diatomists. Diatom Research 20, 1-22. https://doi.org/10.1080/0269249X.2005.9705619

Coulombier, N., Nicolau, E., Le Déan, L., Antheaume, C., Jauffrais, T., Lebouvier, N., 2020. Impact of Light Intensity on Antioxidant Activity of Tropical Microalgae. Marine Drugs 18, 122. https://doi.org/10.3390/md18020122

Custódio, L., Justo, T., Silvestre, L., Barradas, A., Duarte, C.V., Pereira, H., Barreira, L., Rauter, A.P., Alberício, F., Varela, J., 2012. Microalgae of different phyla display antioxidant, metal chelating and 
acetylcholinesterase inhibitory activities. Food Chemistry 131, 134-140. https://doi.org/10.1016/j.foodchem.2011.08.047

Dogra, B., Amna, S., Park, Y.I., Park, J.K., 2017. Biochemical properties of water soluble polysaccharides from photosynthetic marine microalgae Tetraselmis species. Macromolecular Research 25, 172-179. https://doi.org/10.1007/s13233-017-5016-x

Farahin, A.W., Yusoff, F.M., Nagao, N., Basri, M., Shariff, M., 2016. Phenolic content and antioxidant activity of Tetraselmis tetrathele (West) Butcher 1959 cultured in annular photobioreactor. Journal of Environmental Biology 37, 631-639.

Fon-Sing, S., Borowitzka, M.A., 2016. Isolation and screening of euryhaline Tetraselmis spp. suitable for largescale outdoor culture in hypersaline media for biofuels. Journal of Applied Phycology 28, 1-14. https://doi.org/10.1007/s10811-015-0560-2

Foyer, C.H., Noctor, G., 2005. Redox homeostasis and antioxidant signaling: A metabolic interface between stress perception and physiological responses. Plant Cell 17, 1866-1875. https://doi.org/10.1105/tpc.105.033589

Foyer, C.H., Shigeoka, S., 2011. Understanding oxidative stress and antioxidant functions to enhance photosynthesis. Plant Physiology 155, 93-100. https://doi.org/10.1104/pp.110.166181

Franklin, L.A., Forster, R.M., 1997. The changing irradiance environment: consequences for marine macrophyte physiology, productivity and ecology. European Journal of Phycology 32, 207-232. https://doi.org/10.1080/09670269710001737149

Gam, D., Kim, S.Y., Kim, J.W., 2020. Optimization of ultrasound-assisted extraction condition for phenolic compounds, antioxidant activity, and epigallocatechin gallate in lipid-extracted microalgae. Molecules 25, 454. https://doi.org/10.3390/molecules25030454

Gao, K.S., Xu, J.T., Gao, G., Li, Y.H., Hutchins, D.A., Huang, B.Q., Wang, L., Zheng, Y., Jin, P., Cai, X.N., Hader, D.P., Li, W., Xu, K., Liu, N.N., Riebesell, U., 2012. Rising CO2 and increased light exposure synergistically reduce marine primary productivity. Nature Climate Change 2, 519-523. https://doi.org/10.1038/nclimate1507

Geider, R., La Roche, J., 2002. Redfield revisited: variability of C:N:P in marine microalgae and its biochemical basis. European Journal of Phycology 37, 1-17. https://doi.org/10.1017/S0967026201003456

Geider, R.J., Laroche, J., Greene, R.M., Olaizola, M., 1993. Response of the photosynthetic apparatus of Phaeodactylum tricornutum (Bacillariophyceae) to nitrate, phosphate, or iron starvation. Journal of Phycology 29, 755-766. https://doi.org/10.1111/j.0022-3646.1993.00755.x

Giordano, M., Beardall, J., Raven, J.A., 2005. CO2 CONCENTRATING MECHANISMS IN ALGAE: Mechanisms, Environmental Modulation, and Evolution. Annual Review of Plant Biology 56, 99-131. https://doi.org/10.1146/annurev.arplant.56.032604.144052

Goiris, K., Muylaert, K., De Cooman, L., 2015a. Microalgae as a Novel Source of Antioxidants for Nutritional Applications, in: Kim, S.-K. (Ed.), Handbook of Marine Microalgae. Academic Press, Boston, pp. 269280. https://doi.org/10.1016/B978-0-12-800776-1.00017-0

Goiris, K., Muylaert, K., Fraeye, I., Foubert, I., Brabanter, J.D., Cooman, L.D., 2012. Antioxidant potential of microalgae in relation to their phenolic and carotenoid content. Journal of Applied Phycology 24, $1477-$ 1486. https://doi.org/10.1007/s10811-012-9804-6

Goiris, K., Van Colen, W., Wilches, I., León-Tamariz, F., De Cooman, L., Muylaert, K., 2015b. Impact of nutrient stress on antioxidant production in three species of microalgae. Algal Research 7, 51-57. https://doi.org/10.1016/j.algal.2014.12.002

Gordillo, F.J.L., Jimenez, C., Chavarria, J., Niell, F.X., 2001. Photosynthetic acclimation to photon irradiance and its relation to chlorophyll fluorescence and carbon assimilation in the halotolerant green alga Dunaliella viridis. Photosynthesis Research 68, 225-235. https://doi.org/10.1023/A:1012969324756

Gordon, M.H., Magos, P., 1983. The effect of sterols on the oxidation of edible oils. Food Chemistry 10, 141-147. https://doi.org/10.1016/0308-8146(83)90030-4

Goss, R., Garab, G., 2001. Non-photochemical chlorophyll fluorescence quenching and structural rearrangements induced by low $\mathrm{pH}$ in intact cells of Chlorella fusca (Chlorophyceae) and Mantoniella squamata (Prasinophyceae). Photosynthesis Research 67, 185-197. https://doi.org/10.1023/A:1010681511105

Guedes, A. Catarina, Amaro, H.M., Malcata, F.X., 2011. Microalgae as sources of high added-value compoundsa brief review of recent work. Biotechnol Progress 27, 597-613. https://doi.org/10.1002/btpr.575

Guedes, Ana Catarina, Amaro, H.M., Malcata, F.X., 2011. Microalgae as Sources of Carotenoids. Marine Drugs 9, 625-644. https://doi.org/10.3390/md9040625

Guedes, A.C., Amaro, H.M., Pereira, R.D., Malcata, F.X., 2011. Effects of temperature and pH on growth and antioxidant content of the microalga Scenedesmus obliquus. Biotechnology Progress 27, 1218-1224. https://doi.org/10.1002/btpr.649 
Hemaiswarya, S., Raja, R., Kumar, R.R., Ganesan, V., Anbazhagan, C., 2011. Microalgae: A sustainable feed source for aquaculture. World Journal of Microbiology and Biotechnology 27, 1737-1746. https://doi.org/10.1007/s11274-010-0632-z

Henry, G.E., Momin, R.A., Nair, M.G., Dewitt, D.L., 2002. Antioxidant and cyclooxygenase activities of fatty acids found in food. Journal of Agricultural and Food Chemistry 50, 2231-2234. https://doi.org/10.1021/jf0114381

Hinga, K.R., 2002. Effects of pH on coastal marine phytoplankton. Marine Ecology Progress Series 238, 281-300. https://doi.org/10.3354/meps238281

Hu, S., Zhou, B., Wang, You, Wang, Ying, Zhang, X., Zhao, Y., Zhao, X., Tang, X., 2017. Effect of CO2-induced seawater acidification on growth, photosynthesis and inorganic carbon acquisition of the harmful bloomforming marine microalga, Karenia mikimotoi. PLOS ONE 12, e0183289. https://doi.org/10.1371/journal.pone.0183289

Jauffrais, T., Agogué, H., Gemin, M.-P., Beaugeard, L., Martin-Jézéquel, V., 2017. Effect of bacteria on growth and biochemical composition of two benthic diatoms Halamphora coffeaeformis and Entomoneis paludosa. Journal of Experimental Marine Biology and Ecology 495, 65-74. https://doi.org/10.1016/j.jembe.2017.06.004

Jauffrais, T., Jesus, B., Méléder, V., Turpin, V., Russo, A.D.P.G., Raimbault, P., Jézéquel, V.M., 2016. Physiological and photophysiological responses of the benthic diatom Entomoneis paludosa (Bacillariophyceae) to dissolved inorganic and organic nitrogen in culture. Mar Biol 163, 115. https://doi.org/10.1007/s00227-016-2888-9

Jauffrais, T., Séchet, V., Herrenknecht, C., Truquet, P., Savar, V., Tillmann, U., Hess, P., 2013. Effect of environmental and nutritional factors on growth and azaspiracid production of the dinoflagellate Azadinium spinosum. Harmful Algae 27, 138-148. https://doi.org/10.1016/j.hal.2013.05.009

Jiang, Y., Yoshida, T., Quigg, A., 2012. Photosynthetic performance, lipid production and biomass composition in response to nitrogen limitation in marine microalgae. Plant Physiology and Biochemistry 54, 70-77. https://doi.org/10.1016/j.plaphy.2012.02.012

Khatoon, H., Rahman, N.A., Banerjee, S., Harun, N., Suleiman, S.S., Zakaria, N.H., Lananan, F., Hamid, S.H.A., Endut, A., 2014. Effects of different salinities and $\mathrm{pH}$ on the growth and proximate composition of Nannochloropsis sp and Tetraselmis sp isolated from South China Sea cultured under control and natural condition. International Biodeterioration \& Biodegradation 95, 11-18. https://doi.org/10.1016/j.ibiod.2014.06.022

Kramer, D.M., Cruz, J.A., Kanazawa, A., 2003. Balancing the central roles of the thylakoid proton gradient. Trends in Plant Science 8, 27-32. https://doi.org/10.1016/S1360-1385(02)00010-9

Krause, G.H., Weis, E., 1991. Chlorophyll fluorescence and photosynthesis - the basics. Annual Review of Plant $\begin{array}{lllll}\text { Physiology and Plant } & \text { Molecular } & \text { 313-349. }\end{array}$ https://doi.org/10.1146/annurev.pp.42.060191.001525

Lavaud, J., Kroth, P.G., 2006. In diatoms, the transthylakoid proton gradient regulates the photoprotective nonphotochemical fluorescence quenching beyond its control on the xanthophyll cycle. Plant and Cell Physiology 47, 1010-1016. https://doi.org/10.1093/pcp/pcj058

Lavaud, J., Strzepek, R.F., Kroth, P.G., 2007. Photoprotection capacity differs among diatoms: Possible consequences on the spatial distribution of diatoms related to fluctuations in the underwater light climate. Limnology and Oceanography 52, 1188-1194. https://doi.org/10.4319/lo.2007.52.3.1188

Li, Y.T., Han, D.X., Sommerfeld, M., Hu, Q.A., 2011. Photosynthetic carbon partitioning and lipid production in the oleaginous microalga Pseudochlorococcum sp (Chlorophyceae) under nitrogen-limited conditions. Bioresource Technology 102, 123-129. https://doi.org/10.1016/j.biortech.2010.06.036

Lv, J., Yang, X., Ma, H., Hu, X., Wei, Y., Zhou, W., Li, L., 2015. The oxidative stability of microalgae oil (Schizochytrium aggregatum) and its antioxidant activity after simulated gastrointestinal digestion: Relationship with constituents. European Journal of Lipid Science and Technology 117, 1928-1939. https://doi.org/10.1002/ejlt.201400588

Mackey, K.R.M., Morris, J.J., Morel, F.M.M., Kranz, S.A., 2015. Response of Photosynthesis to Ocean Acidification. Oceanography 28, 74-91. https://doi.org/10.5670/oceanog.2015.33

Masojídek, J., Vonshak, A., Torzillo, G., 2010. Chlorophyll fluorescence applications in microalgal mass cultures, in: Suggett, D.J., Prášil, O., Borowitzka, M.A. (Eds.), Chlorophyll a Fluorescence in Aquatic Sciences: Methods and Applications. Dordrecht, Springer Netherlands, pp. 277-292.

Maxwell, K., Johnson, G.N., 2000. Chlorophyll fluorescence-a practical guide. Journal of Experimental Botany 51, 659-668. https://doi.org/10.1093/jexbot/51.345.659

Menguy, E., Dumontet, V., Coulombier, N., Meriot, V., Déan, L.L., Barthelemy, V., Jauffrais, T., 2020. A method to assess algicidal activity of microalgal extracts coupling microalgae produced in stirred closed photobioreactor operating in continuous with pulse amplitude modulated (PAM) fluorometry. MethodsX 7, 101037. https://doi.org/10.1016/j.mex.2020.101037 
Milligan, A.J., Mioni, C.E., Morel, F.M.M., 2009. Response of cell surface pH to pCO2 and iron limitation in the marine diatom Thalassiosira weissflogii. Marine Chemistry 114, 31-36. https://doi.org/10.1016/j.marchem.2009.03.003

Mimouni, V., Ulmann, L., Pasquet, V., Mathieu, M., Picot, L., Bougaran, G., Cadoret, J.-P., Morant-Manceau, A., Schoefs, B., 2012. The potential of microalgae for the production of bioactive molecules of pharmaceutical interest. Current Pharmaceutical Biotechnology 13, 2733-2750. https://doi.org/10.2174/138920112804724828

Mittler, R., 2002. Oxidative stress, antioxidants and stress tolerance. Trends in Plant Science 7, 405-410. https://doi.org/10.1016/S1360-1385(02)02312-9

Miyachi, S., Iwasaki, I., Shiraiwa, Y., 2003. Historical perspective on microalgal and cyanobacterial acclimation to low- and extremely high-CO2 conditions. Photosynthesis Research 77, 139-153. https://doi.org/10.1023/A:1025817616865

Napoleon, C., Raimbault, V., Claquin, P., 2013. Influence of nutrient stress on the relationships between PAM measurements and carbon incorporation in four phytoplankton species. PLOS ONE 8 . https://doi.org/10.1371/journal.pone.0066423

Niki, E., Yoshida, Y., Saito, Y., Noguchi, N., 2005. Lipid peroxidation: Mechanisms, inhibition, and biological effects. Biochemical and Biophysical Research Communications 338, 668-676. https://doi.org/10.1016/j.bbrc.2005.08.072

Paliwal, C., Mitra, M., Bhayani, K., Bharadwaj, V.S.V., Ghosh, T., Dubey, S., Mishra, S., 2017. Abiotic stresses as tools for metabolites in microalgae. Bioresource Technology. https://doi.org/10.1016/j.biortech.2017.05.058

Patterson, G.W., Tsitsa-Tzardis, E., Wikfors, G.H., Gladu, P.K., Chitwood, D.J., Harrison, D., 1993. Sterols of Tetraselmis (Prasinophyceae). Comparative biochemistry and physiology B: Comparative biochemistry 105, 253-0-1993. https://doi.org/10.1016/0305-0491(93)90225-T

Platt, T., Gallegos, C.L., Harrison, W.G., 1981. Photoinhibition of photosynthesis in natural assemblages of marine phytoplankton. Journal of Marine Research 38.

Plaza, M., Cifuentes, A., Ibáñez, E., 2008. In the search of new functional food ingredients from algae. Trends in Food Science \& Technology 19, 31-39. https://doi.org/10.1016/j.tifs.2007.07.012

Ponis, E., Robert, R., Parisi, G., 2003. Nutritional value of fresh and concentrated algal diets for larval and juvenile Pacific oysters (Crassostrea gigas). Aquaculture 221, 491-505. https://doi.org/10.1016/S00448486(03)00075-9

Prior, R.L., Wu, X., Schaich, K., 2005. Standardized Methods for the Determination of Antioxidant Capacity and Phenolics in Foods and Dietary Supplements. Journal of Agricultural and Food Chemistry 53, 42904302. https://doi.org/10.1021/jf0502698

Ptushenko, V.V., Solovchenko, A.E., 2016. Tolerance of the photosynthetic apparatus to acidification of the growth medium as a possible determinant of CO2-tolerance of the symbiotic microalga Desmodesmus sp. IPPAS-2014. Biochemistry Moscow 81, 1531-1537. https://doi.org/10.1134/S0006297916120142

Redfield, A., 1958. The Biological Control of Chemical Factors in the Environment. American Scientist 46, 230A221.

Richard, D., Kefi, K., Barbe, U., Bausero, P., Visioli, F., 2008. Polyunsaturated fatty acids as antioxidants. Pharmacological Research 57, 451-455. https://doi.org/10.1016/j.phrs.2008.05.002

Rios, A.F., Fraga, F., Perez, F.F., Figueiras, F.G., 1998. Chemical composition of phytoplankton and particulate organic matter in the Ria de Vigo (NW Spain). Scientia Marina 62, 257-271. https://doi.org/10.3989/scimar.1998.62n3257

Rodriguez-Amaya, D.B., 2010. Quantitative analysis, in vitro assessment of bioavailability and antioxidant activity of food carotenoids-A review. Journal of Food Composition and Analysis 23, 726-740. https://doi.org/10.1016/j.jfca.2010.03.008

Safafar, H., van Wagenen, J., Møller, P., Jacobsen, C., 2015. Carotenoids, Phenolic Compounds and Tocopherols Contribute to the Antioxidative Properties of Some Microalgae Species Grown on Industrial Wastewater. Marine Drugs 13, 7339-7356. https://doi.org/10.3390/md13127069

Salah, N., Miller, N.J., Paganga, G., Tijburg, L., Bolwell, G.P., Riceevans, C., 1995. Polyphenolic Flavanols as Scavengers of Aqueous Phase Radicals and as Chain-Breaking Antioxidants. Archives of Biochemistry and Biophysics 322, 339-346. https://doi.org/10.1006/abbi.1995.1473

Sansone, C., Brunet, C., 2019. Promises and Challenges of Microalgal Antioxidant Production. Antioxidants 8, 199. https://doi.org/10.3390/antiox 8070199

Sathasivam, R., Ki, J.S., 2018. A Review of the Biological Activities of Microalgal Carotenoids and Their Potential Use in Healthcare and Cosmetic Industries. Marine Drugs 16, 26. https://doi.org/10.3390/md16010026

Schreiber, U., Bilger, W., Neubauer, C., 1995. Chlorophyll Fluorescence as a Nonintrusive Indicator for Rapid Assessment of In Vivo Photosynthesis, in: Schulze, E.-D., Caldwell, M.M. (Eds.), Ecophysiology of 
Photosynthesis. Springer Berlin Heidelberg, Berlin, Heidelberg, pp. 49-70. https://doi.org/10.1007/9783-642-79354-7_3

Smerilli, A., Balzano, S., Maselli, M., Blasio, M., Orefice, I., Galasso, C., Sansone, C., Brunet, C., 2019. Antioxidant and Photoprotection Networking in the Coastal Diatom Skeletonema marinoi. Antioxidants 8, 154. https://doi.org/10.3390/antiox8060154

Smerilli, A., Orefice, I., Corato, F., Gavalás Olea, A., Ruban, A.V., Brunet, C., 2016. Photoprotective and antioxidant responses to light spectrum and intensity variations in the coastal diatom Skeletonema marinoi. Environmental Microbiology n/a-n/a. https://doi.org/10.1111/1462-2920.13545

Solovchenko, A., Khozin-Goldberg, I., 2013. High-CO2 tolerance in microalgae: possible mechanisms and implications for biotechnology and bioremediation. Biotechnology Letters 35, 1745-1752. https://doi.org/10.1007/s10529-013-1274-7

Takahashi, S., Murata, N., 2005. Interruption of the Calvin cycle inhibits the repair of Photosystem II from photodamage. Biochimica et Biophysica Acta (BBA) - Bioenergetics 1708, 352-361. https://doi.org/10.1016/j.bbabio.2005.04.003

Talero, E., García-Mauriño, S., Ávila-Román, J., Rodríguez-Luna, A., Alcaide, A., Motilva, V., 2015. Bioactive compounds isolated from microalgae in chronic inflammation and cancer. Marine Drugs 13, 6152-6209. https://doi.org/10.3390/md13106152

Thinh, L.V., Renaud, S.M., Parry, D.L., 1999. Evaluation of recently isolated Australian tropical microalgae for the enrichment of the dietary value of brine shrimp, Artemia nauplii. Aquaculture 170, 161-173. https://doi.org/10.1016/S0044-8486(98)00400-1

Touloupakis, E., Cicchi, B., Benavides, A.M.S., Torzillo, G., 2016. Effect of high pH on growth of Synechocystis sp PCC 6803 cultures and their contamination by golden algae (Poterioochromonas sp). Applied Microbial and Cell Physiology 100, 1333-1341. https://doi.org/10.1007/s00253-015-7024-0

Walne, P.R., 1966. Experiments in the large scale culture of the larvae of Ostrea Edulis L., Fishery investigations (Great Britain. Ministry of Agriculture, Fisheries and Food). H.M.S.O., London.

Wijffels, R.H., Barbosa, M.J., Eppink, M.H.M., 2010. Microalgae for the production of bulk chemicals and biofuels. Biofuels, Bioproducts and Biorefining 4, 287-295. https://doi.org/10.1002/bbb.215

Williamson, C.J., Perkins, R., Yallop, M.L., Peteiro, C., Sanchez, N., Gunnarsson, K., Gamble, M., Brodie, J., 2018. Photoacclimation and photoregulation strategies of Corallina (Corallinales, Rhodophyta) across the NE Atlantic. European Journal of Phycology 53, 290-306. https://doi.org/10.1080/09670262.2018.1442586

Worden, A.Z., Nolan, J.K., Palenik, B., 2004. Assessing the dynamics and ecology of marine picophytoplankton: The importance of the eukaryotic component. Limnology and Oceanography 49, 168-179. https://doi.org/10.4319/lo.2004.49.1.0168

Wu, H.Y., Roy, S., Alami, M., Green, B.R., Campbell, D.A., 2012. Photosystem II photoinactivation, repair, and protection in marine centric diatoms. Plant Physiology 160, (1, 464-476. https://doi.org/10.1104/pp.112.203067

Wu, Y., Gao, K., Riebesell, U., 2010. CO2-induced seawater acidification affects physiological performance of the marine diatom Phaeodactylum tricornutum. Biogeosciences 7, 2915-2923. http://dx.doi.org/10.5194/bg-7-2915-2010

Wu, Y.P., Beardall, J., Gao, K.S., 2015. Physiological responses of a model marine diatom to fast pH changes: Special implications of coastal water acidification. PLOS ONE 10, 10. https://doi.org/10.1371/journal.pone.0141163

Xia, B., Sui, Q., Sun, X., Han, Q., Chen, B., Zhu, L., Qu, K., 2018. Ocean acidification increases the toxic effects of TiO2 nanoparticles on the marine microalga Chlorella vulgaris. Journal of Hazardous Materials 346, 1-9. https://doi.org/10.1016/j.jhazmat.2017.12.017

Xiang, Y.B., Zhang, J., Weeks, D.P., 2001. The Cia5 gene controls formation of the carbon concentrating mechanism in Chlamydomonas reinhardtii. PNAS 98, 5341-5346. https://doi.org/10.1073/pnas.101534498

Yoshida, Y., Niki, E., 2003. Antioxidant Effects of Phytosterol and Its Components. Journal of Nutritional Science and Vitaminology 49, 277-280. https://doi.org/10.3177/jnsv.49.277

Yuan, J.-P., Peng, J., Yin, K., Wang, J.-H., 2011. Potential health-promoting effects of astaxanthin: A high-value carotenoid mostly from microalgae. Molecular Nutrition and Food Research 55, 150-165. https://doi.org/10.1002/mnfr.201000414

Zhang, Y.-M., Chen, H., He, C.-L., Wang, Q., 2013. Nitrogen starvation induced oxidative stress in an oilproducing green alga Chlorella sorokiniana $\mathrm{C} 3 . \quad$ PLoS ONE 8, e69225. https://doi.org/10.1371/journal.pone.0069225 

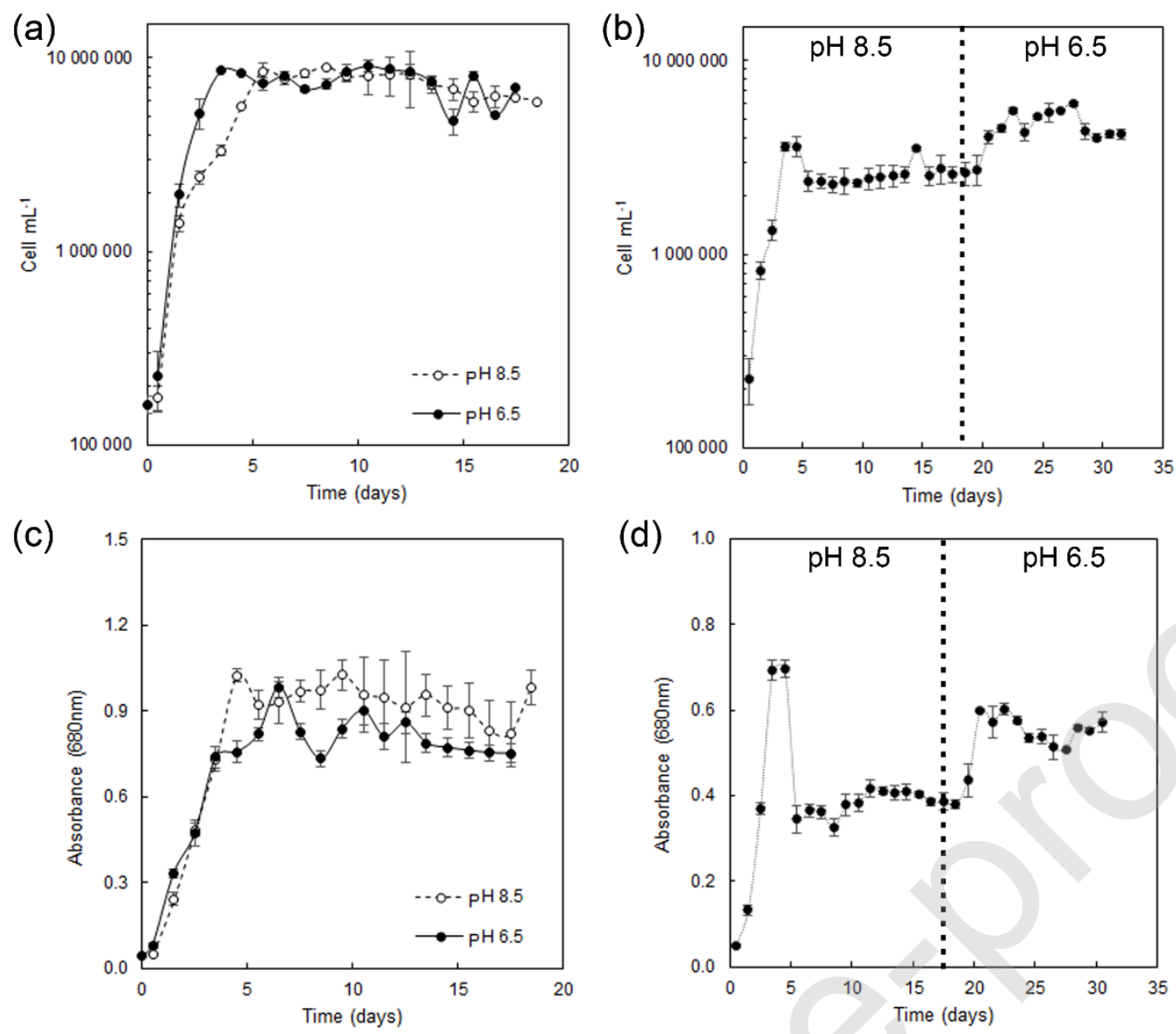

Fig. 1 (a), (b) Cell concentration in Cell mL-1; (c), (d) Absorbance at $680 \mathrm{~nm}$ of Tetraselmis sp. cultured in batch (left panels) and continuous (right panels) cultures in PBRs at pH 8.5 and 6.5 over time (days). Data are expressed as mean \pm standard error $(\mathrm{SE}, \mathrm{n}=3$ ) 

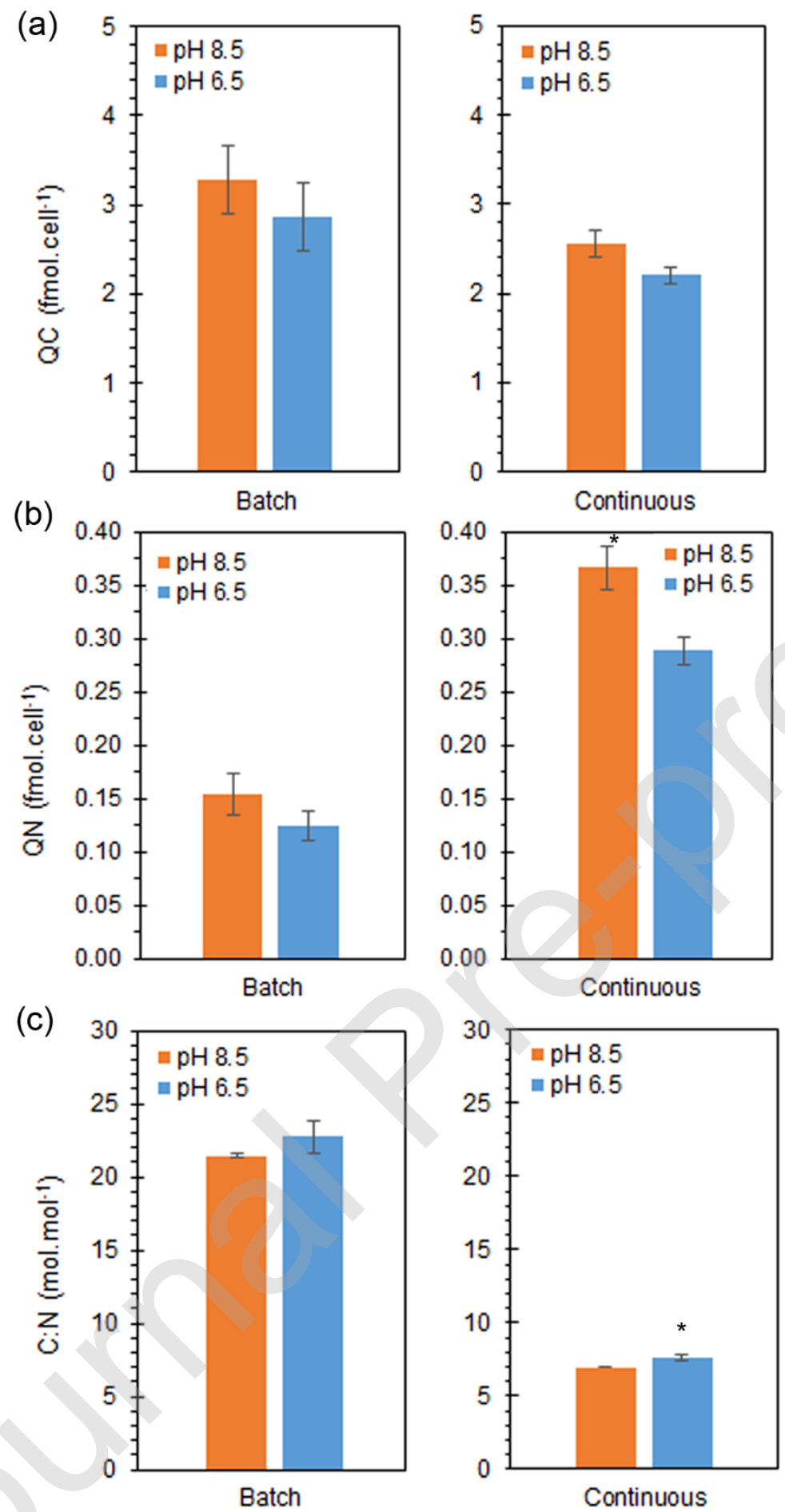

Fig. 2 (a) Carbon cell quota (fmol cell ${ }^{-1}$ ) QC; (b) Nitrogen cell quota QN (fmol cell ${ }^{-1}$ ); (c) C:N (Carbon:Nitrogen) ratio of Tetraselmis sp. in batch culture at stationary phase and in continuous culture at steady state at $\mathrm{pH} 8.5$ and 6.5. * indicates significant differences between conditions $(\mathrm{P}-\mathrm{value}<0.05)$. Data are expressed as mean \pm standard error ( $\mathrm{SE}, \mathrm{n}=6$ in batch and 12 in continuous culture) 
(a)

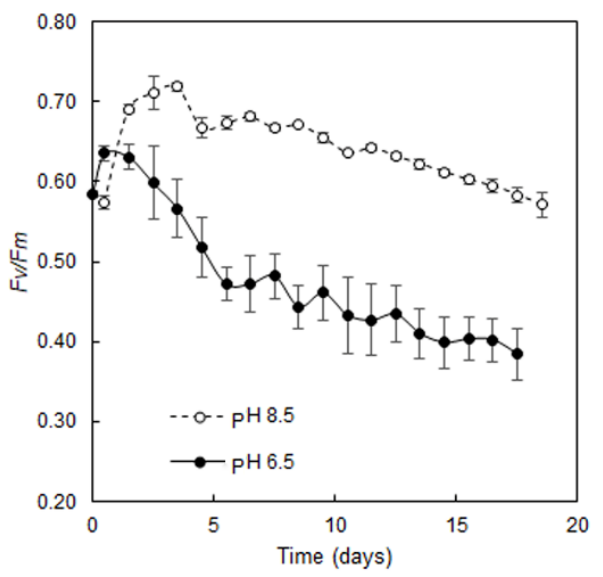

(b)

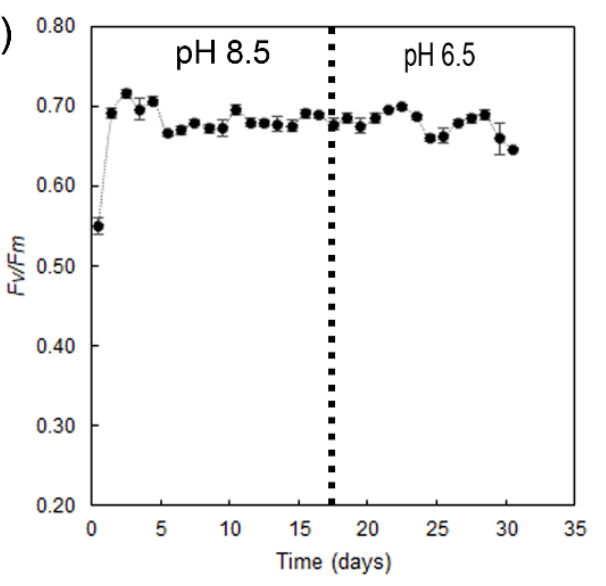

Fig. 3 (a), (b) Maximum quantum light utilization efficiency of photosystem II (PSII, Fv/Fm) of Tetraselmis sp. in batch (left panels) and continuous (right panels) cultures in PBRs at pH 8.5 and 6.5 over time (days). Data are expressed as mean \pm standard error $(\mathrm{SE}, \mathrm{n}=3)$
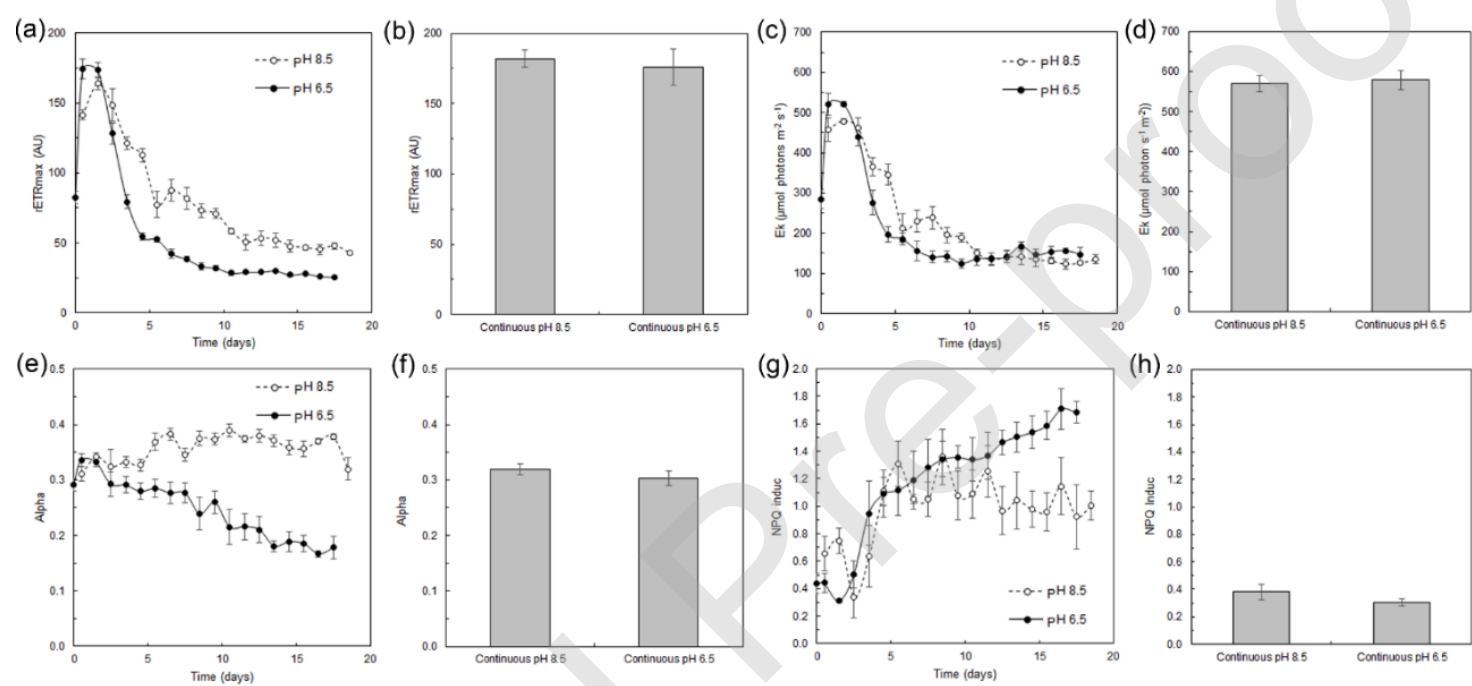

Fig. 4 Photosynthetic parameters obtained from rapid light curves carried out on Tetraselmis sp. in batch (a, $\mathrm{c}, \mathrm{e}, \mathrm{g}$ ) and continuous (b, d, f, h) cultures in PBRs at $\mathrm{pH} 8.5$ and 6.5. (a), (b) Maximum electron transport rate rETRmax in AU; (c), (d). light saturation coefficient Ek in $\mu$ mol photons $\mathrm{m}^{-2} \mathrm{~s}^{-1} ;$ (e), (f) Maximum light utilization coefficient for photosystem II Alpha; (g), (h).Non-Photochemical Quenching induced during RLC NPQ induc. Data are expressed as mean \pm standard error $(\mathrm{SE}, \mathrm{n}=3$ ) 

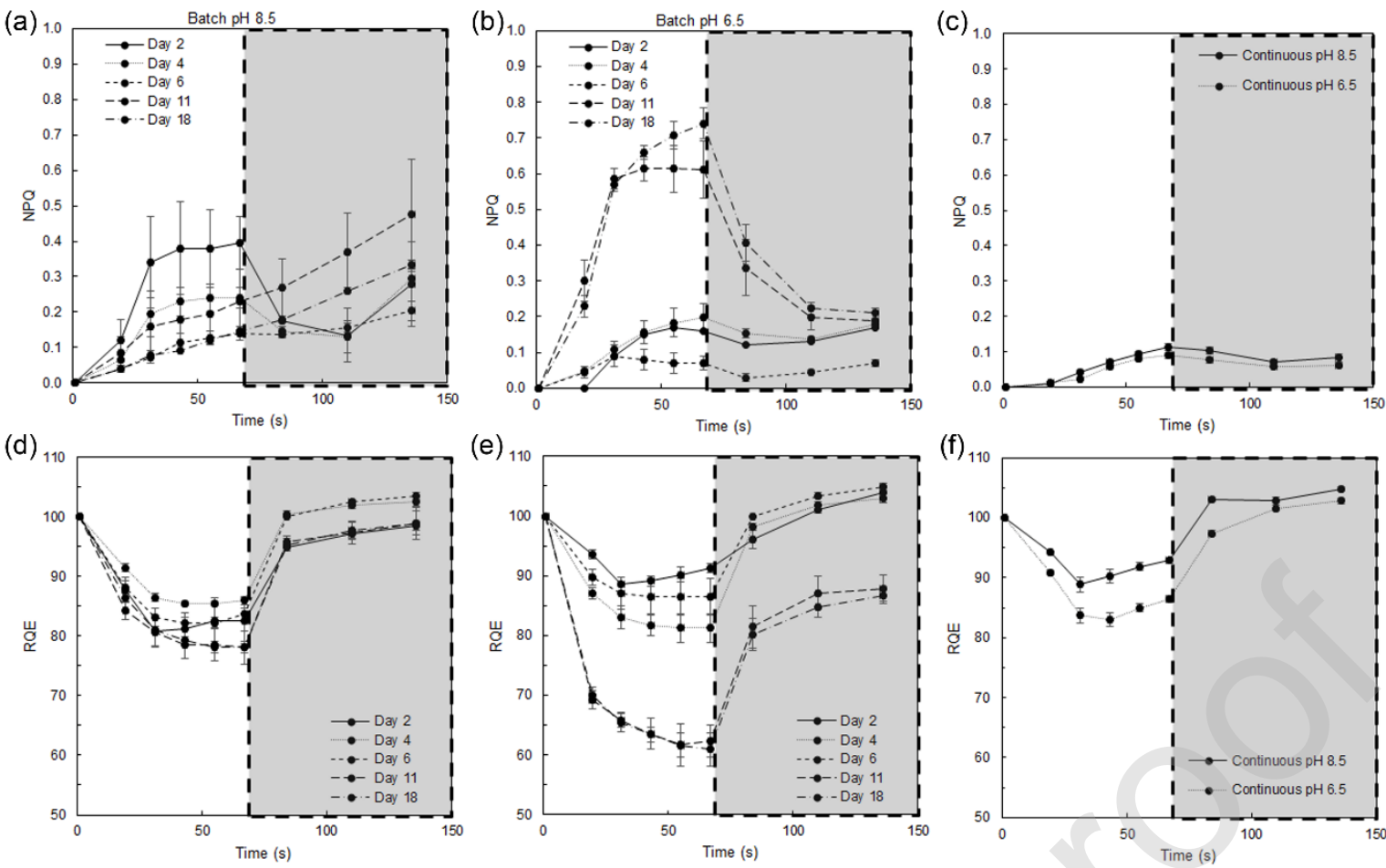

Fig. 5 (a), (b), (c) Non-Photochemical Quenching (NPQ) over the induction (white background) and dark recovery (grey background) (d), (e), (f) Relative Quantum Efficiency (RQE) of Tetraselmis sp. in batch (days $2,4,6,11,18$ ) and continuous cultures (the two steady states) in PBRs at pH 6.5 and 8.5. Data are expressed as mean \pm standard error $(\mathrm{SE}, \mathrm{n}=3)$
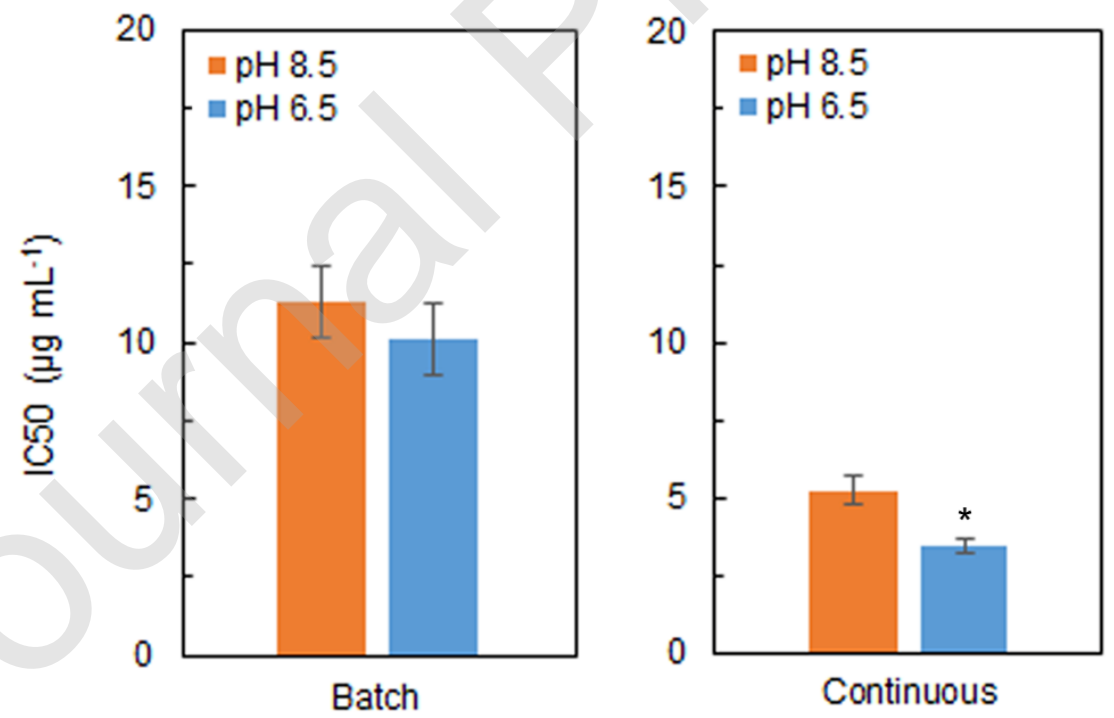

Fig. 6 Evolution of the antioxidant activities $\left(\mathrm{IC}_{50}, \mu \mathrm{g} \mathrm{mL} \mathrm{m}^{-1}\right)$ of Tetraselmis sp. extracts in batch culture at stationary phase and in continuous culture at steady state at $\mathrm{pH} 8.5$ and 6.5. * indicates significant differences between conditions (P-value<0.05). Data are expressed as mean \pm standard error ( $\mathrm{SE}, \mathrm{n}=6$ in batch and 12 in continuous culture). Reference compounds trolox $\left(\mathrm{IC}_{50}=0.24 \mu \mathrm{g} \mathrm{mL}-1\right)$ and $\alpha$-tocopherol $\left(\mathrm{IC}_{50}=1.30\right.$ $\left.\mu \mathrm{g} \mathrm{mL} \mathrm{m}^{-1}\right)$ 


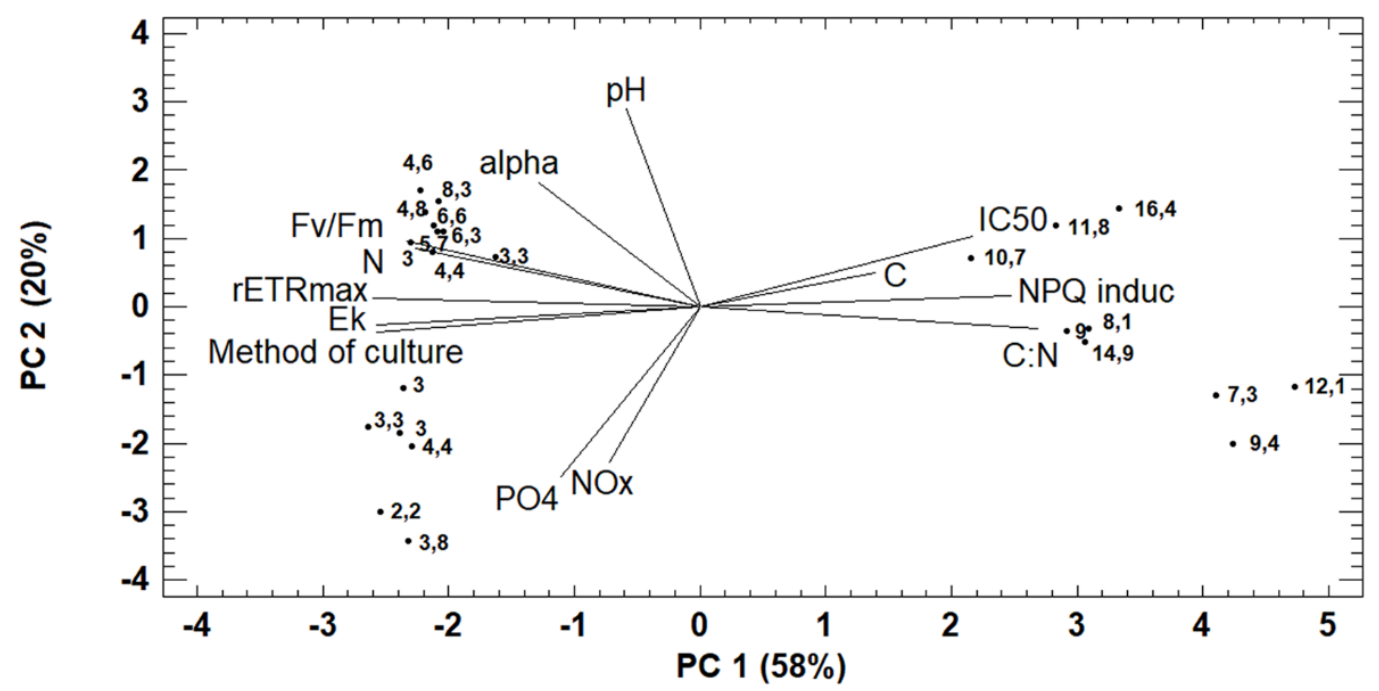

Fig. 7 Results of the first and second component analysis influencing the antioxidant activity (IC 50 , black dot with their associated values) of Tetraselmis sp.. Fv/Fm (Maximum quantum light utilization efficiency of Photosystem II), rETRmax (relative maximum electron transport rate), Ek (light saturation coefficient in $\mu$ mol photons $\mathrm{m}^{-2} \mathrm{~s}^{-1}$ ), alpha (maximum light utilisation coefficient for photosystem II), NPQ induc (NonPhotochemical Quenching induced during RLC), NOX (nitrate + nitrite) at sampling time, N and C (nitrogen and carbon quotas), $\mathrm{C}: \mathrm{N}$ (carbon:nitrogen ratio) 
Table 1 Cell growth parameters, maximum growth rate ( $\mu$ max), latency time (lambda) and maximum cell concentration (Cmax) of Tetraselmis sp. cultured in PBRs in batch culture at $\mathrm{pH} 8.5$ and 6.5. Data are calculated using a Gompertz model and expressed as mean \pm standard error $(\mathrm{SE}, \mathrm{n}=3)$. Differences were considered significant at $\mathrm{p}<0.05$

\begin{tabular}{ccccc} 
Batch culture & $\mathrm{pH} 8.5$ & $\mathrm{pH} 6.5$ & F-ratio & $\mathrm{P}(\alpha=0.05)$ \\
\hline$\mu \max \left(\right.$ day $\left.^{-1}\right)$ & $1.48 \pm 0.16$ & $2.45 \pm 0.18$ & 15.74 & $\mathbf{0 . 0 2}$ \\
Lambda $($ day $)$ & $0.18 \pm 0.03$ & $0.44 \pm 0.04$ & 22.57 & $\mathbf{0 . 0 1}$ \\
Cmax $\left(\times 10^{6}\right.$ cells $\left.\mathrm{mL}^{-1}\right)$ & $7.10 \pm 0.83$ & $7.51 \pm 0.21$ & 2.11 & 0.22 \\
Adjusted ${ }^{2}$ & $0.97 \pm 0.01$ & $0.97 \pm 0.01$ & - & - \\
\hline
\end{tabular}

Table 2 Results of the statistical analysis on photosynthetic parameters obtained from rapid light curves carried out on Tetraselmis sp. in batch (General linear model) and continuous cultures (Kruskal Wallis test) in PBRs at pH 8.5 and 6.5. Fv/Fm, Maximum quantum light utilization efficiency of Photosystem II (PSII); rETRmax, maximum electron transport rate in AU; Ek, light saturation coefficient in $\mu$ mol photons $\mathrm{m}^{-2} \mathrm{~s}^{-1}$; Alpha, maximum light utilisation coefficient for photosystem II; NPQ induc, Non-Photochemical Quenching induced during RLC. Values are significantly different when $\mathrm{P}<0.05$.

\begin{tabular}{ccccc} 
Batch culture & pH F-ratio & pH P-value & Time F-ratio & Time P-value \\
\hline Fv/Fm & 283.84 & $<0.001$ & 6.63 & $<0.001$ \\
rETRmax & 99.23 & $<0.001$ & 61.30 & $<0.001$ \\
alpha & 171.3 & $<0.001$ & 1.47 & 0.11 \\
Ek & 6.44 & $<0.05$ & 50.30 & $<0.001$ \\
NPQ induc & 16.11 & $<0.001$ & 6.87 & $<0.001$ \\
\hline Continuous culture & $\mathrm{pH} 8.5$ & $\mathrm{pH} 6.5$ & \multicolumn{2}{c}{ P-value } \\
\hline Fv/Fm & $0.71 \pm 0.01$ & $0.67 \pm 0.03$ & $<0.05$ \\
rETRmax & $181.90 \pm 6.20$ & $176.02 \pm 12.80$ & 0.56 \\
alpha & $0.32 \pm 0.01$ & $0.30 \pm 0.01$ & 0.56 \\
Ek & $570.62 \pm 19.83$ & $578.62 \pm 24.47$ & \multicolumn{2}{c}{0.70} \\
NPQ induc & $0.38 \pm 0.06$ & $0.31 \pm 0.03$ & \multicolumn{2}{c}{0.72}
\end{tabular}

Table 3 Results of the general linear model analysis on Non-Photochemical Quenching (NPQ) and Relative Quantum Efficiency (RQE) of Tetraselmis sp. in batch (sampling day 2, 4, 6, 11 and 18) and continuous cultures (steady states) in PBRs at pH 6.5 and 8.5 over the induction and dark recovery (Time). Values are significantly different when $\mathrm{P}<0.05$

\begin{tabular}{ccccc}
\hline & \multicolumn{2}{c}{ NPQ } & \multicolumn{2}{c}{ RQE } \\
\hline Batch culture & F-ratio & P-value & F-ratio & P-value \\
\hline A: $\mathrm{pH}$ & 8.41 & $<0.01$ & 27.57 & $<0.001$ \\
B: Sampling Day & 31.1 & $<0.001$ & 42.37 & $<0.001$ \\
C: Time & 19.17 & $<0.001$ & 60.62 & $<0.001$ \\
$\mathrm{~A} * \mathrm{~B}$ & 27.95 & $<0.001$ & 22.66 & $<0.001$ \\
$\mathrm{~A} * \mathrm{C}$ & 5.38 & $<0.001$ & 0.58 & 0.79 \\
$\mathrm{~A} * \mathrm{~B} * \mathrm{C}$ & 3.26 & $<0.001$ & 0.48 & 0.97 \\
\hline \hline Continuous culture & F-ratio & PPQ & \multicolumn{3}{c}{ RQE } \\
\hline A: $\mathrm{pH}$ & 17.3 & $<0.01$ & 22.91 & $<0.01$ \\
B: Time & 47.68 & $<0.001$ & 28.98 & $<0.001$ \\
\hline \hline
\end{tabular}


Table 4 Results of the multifactorial and single ANOVAs to assess the effect of pH, sampling day (early and late stationary phase), and culture systems (batch $v s$ continuous cultures) on antioxidant activities $\left(\mathrm{IC}_{50}, \mu \mathrm{g}\right.$ $\mathrm{mL}^{-1}$ ) of Tetraselmis sp.. Values are significantly different when $\mathrm{P}<0.05$

\begin{tabular}{ccc}
\hline & \multicolumn{2}{c}{$\mathrm{IC}_{50}$} \\
\hline Batch culture & F-ratio & P-value \\
\hline A: Sampling Day & 0.53 & 0.49 \\
$\mathrm{~B}: \mathrm{pH}$ & 0.52 & 0.49 \\
$\mathrm{~A} * \mathrm{~B}$ & 1.8 & 0.22 \\
\hline & \multicolumn{3}{c}{$\mathrm{IC}_{50}$} \\
\hline Continuous culture & F-ratio & P-value \\
\hline $\mathrm{pH}$ & 6.65 & 0.02 \\
\hline \hline Batch $v s$ continuous culture & \multicolumn{3}{c}{$\mathrm{IC}_{50}$} \\
\hline $\mathrm{A}:$ Culture system & F-ratio & P-value \\
$\mathrm{B}: \mathrm{pH}$ & 58.62 & $<0.001$ \\
$\mathrm{~A} * \mathrm{~B}$ & 3.4 & 0.08 \\
\hline \hline
\end{tabular}

